\title{
Pros and Cons of Structure for Motion Embarked on a Vehicle to Survey Slopes along Transportation Lines Using 3D Georeferenced and Coloured Point Clouds
}

\author{
Jérémie Voumard ${ }^{1, *}$, Marc-Henri Derron ${ }^{1}$, Michel Jaboyedoff ${ }^{1}$, Pierrick Bornemann ${ }^{2}$ and \\ Jean-Philippe Malet ${ }^{2}$ D \\ 1 Risk Analysis Group, Institute of Earth Sciences, FGSE, University of Lausanne, 1015 Lausanne, Switzerland; \\ marc-henri.derron@unil.ch (M.-H.D.); michel.jaboyedoff@unil.ch (M.J.) \\ 2 Institut de Physique du Globe de Strasbourg, CNRS UMR 7516, University of Strasbourg, 67084 Strasbourg, \\ France; pierrick.bornemann@live-cnrs.unistra.fr (P.B.); jeanphilippe.malet@unistra.fr (J.-P.M.) \\ * Correspondence: jeremie.voumard@unil.ch; Tel.: +41-21-692-3547
}

Received: 12 October 2018; Accepted: 30 October 2018; Published: 3 November 2018

\begin{abstract}
We discuss the different challenges, pros and cons of the fairly new Structure for Motion (SfM) embarked on a vehicle (SfM-EV) technique for slope surveys along transportation network tracks using action cameras embarked on standard moving vehicles. This low-cost technique generates georeferenced and coloured 3D point clouds without using any ground control points. Four action cameras, two of which had an integrated GNSS chip, were used to collect a series of pictures of tracksides at a rate of two images per second each. The SfM-EV results were compared with the results of seven other 3D survey techniques to evaluate the precision and accuracy of this technique, demonstrating the ability of this simple setting to generate 3D scenes. Different platforms for the cameras were tested, such as a bike, car, train, funicular, helicopter and so on. The SfM-EV technique was also tested on several study sites to highlight its strengths and weaknesses and obtain data, such as the density of points, equations of errors, overlap ratios and image resolution. The precision of the SfM-EV results was sufficient for detecting topographical changes close to the track for a volume of $\sim 1 \mathrm{dm}^{3}$ and the absolute positioning obtained with a low sky obstruction was approximately $5 \mathrm{~m}$. The precision of SfM-EV was of a similar order to the other techniques, with an order of magnitude of a few centimetres. This approach possesses a low price-result quality ratio and is very simple to use. The possibility of using any type of vehicle for surveying is an advantage, especially for transportation track embankments.
\end{abstract}

Keywords: structure from motion; SfM embarked on a vehicle; topographical survey; transportation network; point clouds; natural hazard

\section{Introduction}

Transportation networks, which are essential elements in society, are threatened by events that could generate a track closure [1-17]. They must be continuously maintained and surveyed to guarantee their functioning [15]. Their supervision is performed for the track itself and around it, to avoid/prevent external factors that can corrupt the track efficiency. External factors such as natural hazards may affect tracks and interrupt traffic.

To survey and characterize natural hazard events along roads and railway tracks, 3D terrain modelling of slopes around track paths is commonly used because it can provide data to analyse changes [18]). Several techniques have been developed to digitize the terrain such as scanning total station, light detection and ranging (LiDAR), a global navigation satellite system (GNSS) or photogrammetry with an unmanned aerial vehicle (UAV). In addition, 3D remote sensing techniques 
are also becoming widely used for slope investigations due to their ability to represent the geometry of gravitational processes (mass movements, debris flows, rockfalls, etc.) and their evolution over time by comparing 3D point clouds acquired at different time steps [19-21]. Thus, LiDAR [22-24] and photogrammetrically derived point clouds [25-29] are used to monitor slope evolution.

Currently, transportation networks are commonly surveyed with mobile laser scanning (MLS) or UAV-based Structure for Motion (SfM) processing. Although very accurate, LiDAR technology is expensive and highly demanding from a logistic point of view [30]. Images from UAV using SfM generate 3D point clouds [20,31] which may provide information of slope changes near transportation lines. However, the environment around the tracks, such as trees or heavy traffic, may provide unsatisfactory results or may encounter security difficulties during the acquisition.

Here, we apply the SfM embarked on a vehicle (SfM-EV) technique, which has been widely used in street view methodology [32] but which has not yet been applied to a geohazards survey. This low-cost technique generates 3D coloured point clouds georeferenced by SfM processing of images taken from a moving vehicle. Strengths and weaknesses of this SfM-EV technique are discussed and it is compared with the other types of survey techniques (terrestrial, handheld, mobile and airborne LiDAR, UAV-based SfM and scanning total station) to evaluate its feasibility to survey transportation tracks and neighbouring slopes. We quantify precisions and accuracies on a cliff and we evaluate the influence of the platform distance and the velocity of the acquisition on a test site, which provide the basis for future applications. The results show that the topography along a transportation network can be surveyed using SfM-EV and that a slope change of one litre can be identified.

\section{SfM Embarked on a Vehicle}

"Classical" SfM, without a moving platform, has exponentially grown in the geosciences since approximately 2010 [19,20], facilitated by computers with processing power that is sufficient to process image sets in an acceptable processing time. Currently, personal computers are able to process an SfM process of few hundred images in less than one day. Hence, SfM is used in several domains where object modelling is common, as in the geosciences [20,33], archaeology [34], geomatics, architecture [35], agriculture [36] or gaming, computer films and computer vision [37]. With the SfM technique, we can expect an accuracy of a few millimetres for a distance of the object to the camera of a few tens of decimetres, of a few centimetres for a distance of tens of metres and of centimetres to metres for a distance of a few hundreds of metres [20,38]. The main disadvantages are: the possible deformation of the modelled topography, the poor vegetation modelling, the over-smoothing of the topography, the necessity of optimal conditions of acquisition and the necessity of a ground control point (GCP) to georeference the point clouds.

The main steps of classical SfM processing are: (1) feature detection and matching [39]; (2) sparse reconstruction and bundle adjustment [26,40-42]; (3) dense 3D point cloud generation [38,43,44]; and (4) surface reconstruction and visualization [38].

SfM-EV is a variation of the standard SfM. With the SfM-EV, the sensor is in movement and takes images without stopping the sensor (Figure 1). In some ways, since the camera is moving, we can describe SfM embarked on a vehicle similar to traditional SfM, which is in fact often the case using UAV as the camera platform. In SfM-EV, cameras are mounted on different vehicle types and take images of the track and the adjacent slopes from the road or the railway while the vehicle is driving, similar to Google street view acquisition [45]. The sensor movement and positioning generate issues that are linked to the image quality and are directly affected by the sensor velocity and the changes in the environment lighting. The images can be blurred, under- and over-exposed and the white not well balanced. We also observed rolling shutter distortion and shadows from other vehicles, track infrastructures and so on. 


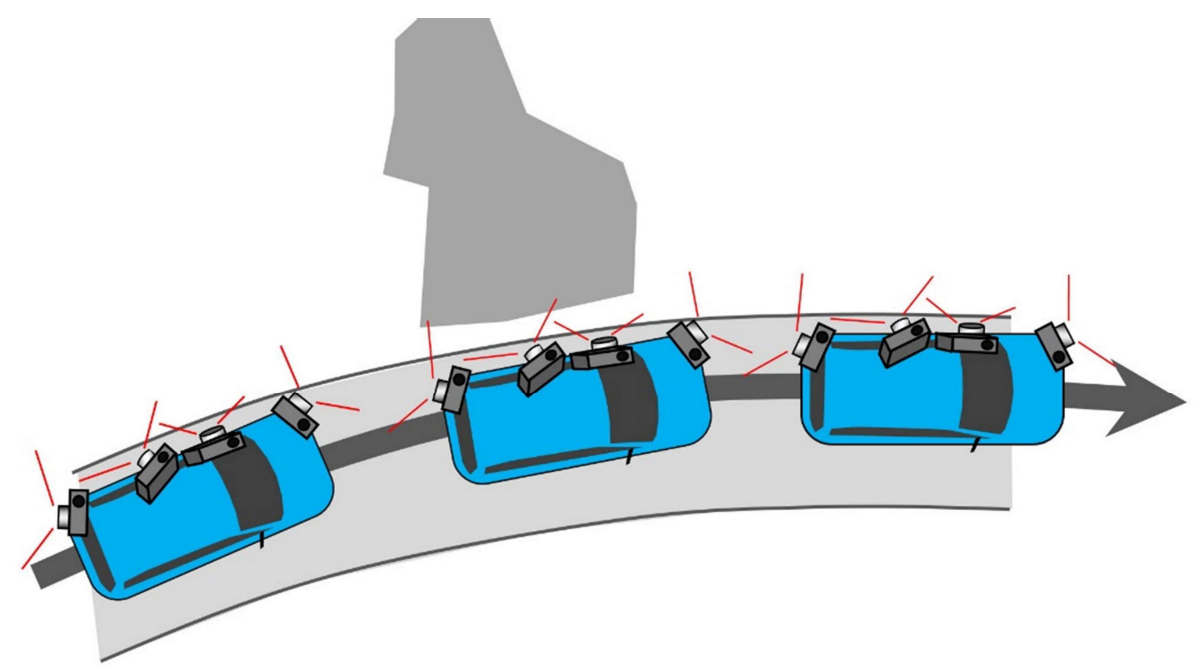

Figure 1. Concept of structure for motion embarked on a vehicle (SfM-EV). Note the different tilt and pan angles of the action cameras.

Traffic conditions must be taken into account in order to plan the acquisition. Moreover, SfM-EV along a long linear object is challenging because in case of error in the model construction, this bias will grow along the model length. The cameras of SfM-EV can be mounted on several platforms such as cars, trains, bikes, boats, helicopters and pedestrians.

The accuracy of colourized 3D point clouds obtained with SfM-EV depends on several factors. As already mentioned, poor quality images, low resolution images, or insufficient cover of the areaa too narrow view angle around the object or a too small overlap of images $(<60 \%)$-will produce degraded results and hence, poor accuracy of the 3D point clouds. If GNSS coordinates of images are degraded (an error greater than $20 \mathrm{~m}$ ), wrong (an error greater than $50 \mathrm{~m}$ ) or missing, processes of the 3D point cloud processing will also generate degraded (an error greater than $10 \mathrm{~m}$ ), wrong (an error greater than $30 \mathrm{~m}$ ) or impossible automatic scaling and georeferencing even though the images are properly distributed, and their quality is perfect.

After a presentation of the data and techniques used in this study, the results of SfM-EV are presented in three sections. The first part refers to the precision of the SfM-EV technique based on action cameras that were acquired and produced in 2015-2016, integrating a GNSS for two of them. The second part focuses on the technique's automatic georeferencing (accuracy). The third part covers the comparison of the SfM-EV techniques with seven other tested techniques. Finally, some examples of 3D point clouds from SfM-EV are presented.

\section{Data and Techniques}

\subsection{Cameras and Acquisition Configuration}

\subsubsection{Camera Types}

Action cameras were chosen as the sensor type because of their numerous advantages. Reflex cameras were mainly discarded because of their high cost, their low robustness and their complicated attachment on a vehicle. After different tests with several camera models (GoPro Hero3+ [46] and Garmin Virb XE [47]) and numbers (up to six cameras), four GoPro action cameras were used to acquire images. Two of them are the Hero4 Silver [48] model while the two others are the Hero5 [49] black model (Table 1). The main difference between the models is the presence of a GNSS chip that is integrated in the Hero5 model. 
Table 1. Attributes of the GoPro used in the SfM-EV technique.

\begin{tabular}{|c|c|c|}
\hline Cameras Features & GoPro HERO4 Silver & GoPro HERO5 \\
\hline Resolution & \multicolumn{2}{|c|}{$12 \mathrm{MP}$} \\
\hline Time lapse & \multicolumn{2}{|c|}{2 images per second } \\
\hline Release & 08.2014 & 08.2015 \\
\hline Launch price & 380 EUR & 430 EUR \\
\hline GNSS (GPS constellation) & No & Yes \\
\hline Set focus & No & Yes \\
\hline Used MicroSD card capacity & \multicolumn{2}{|c|}{$64 \mathrm{~GB}$} \\
\hline Number of images with 64 GB card & \multicolumn{2}{|c|}{24,337} \\
\hline Acquisition time @ 2 fps & \multicolumn{2}{|c|}{$3 \mathrm{~h} 22 \mathrm{~min}$} \\
\hline Acquisition time @ $1 \mathrm{fps}$ & \multicolumn{2}{|c|}{$6 \mathrm{~h} 44 \mathrm{~min}$} \\
\hline Acquisition time @ 0.5 fps & \multicolumn{2}{|c|}{$13 \mathrm{~h} 28 \mathrm{~min}$} \\
\hline Vertical FOV & \multicolumn{2}{|c|}{$94.4^{\circ}$} \\
\hline Horizontal FOV & \multicolumn{2}{|c|}{$122.6^{\circ}$} \\
\hline Diagonal FOV & \multicolumn{2}{|c|}{$149.2^{\circ}$} \\
\hline Focal length equivalence & $17.2 \mathrm{~mm}$ & $14 \mathrm{~mm}$ \\
\hline
\end{tabular}

The advantages of GoPro cameras for SfM-EV are their small size, high robustness, easy mounting, easy power supply, fisheye lens for capturing a large view, time lapse mode and remote-control capability. Their inconveniences are the low battery capacity, the medium image quality and the non-settable automatic exposure that generates over- or under-exposed images.

\subsubsection{Sensors and Data Acquisition}

Cameras can be mounted on vehicles exclusively with suction cups positioned on the windows or the vehicle body (Figure 2A,C). To improve the point of view from a car, a mast was built to increase the height position at approximately $3.15 \mathrm{~m}$ from the ground. The cameras for slope surveys from a train, a funicular and a helicopter were positioned on the windows or the vehicle body with suction cups (Figure 2C). During tests using a bike and on foot, two cameras were held in one hand, while the tests by plane were carried out with one camera held in one hand.

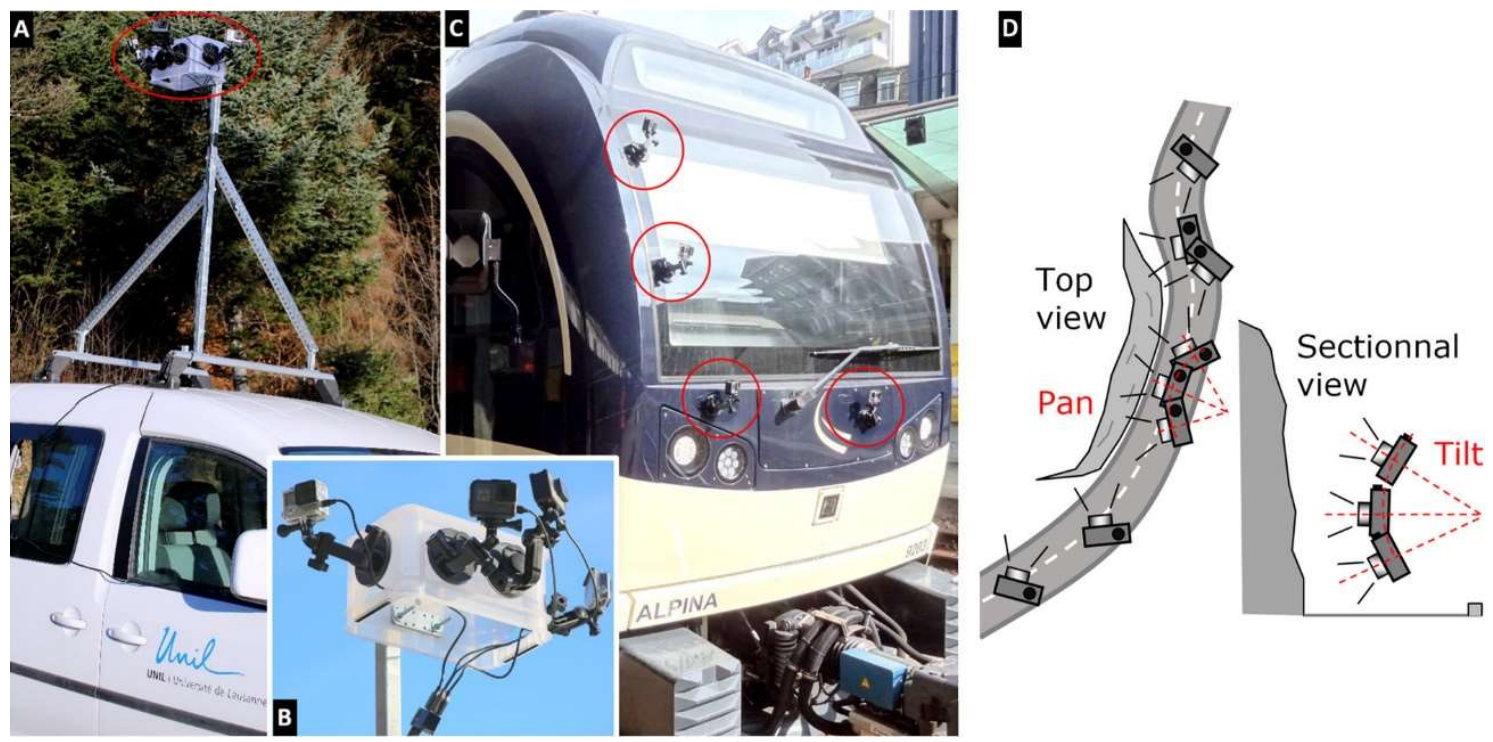

Figure 2. SfM-EV system on a vehicle. (A): Cameras mounted on a mast on the vehicle roof; (B): Details of the four cameras' assembly with suction cups and power cables (note the tilt and pan variations); (C): Cameras mounted on the train body; (D): Schematic view of the tilt and pan variation of the cameras (from Voumard et al., 2017). 
Since the GoPro batteries last up to few hours, it was necessary to add a power supply to have enough energy for at least half a day. Cameras were then linked to a 12-volt car plug using a USB adapter.

The four cameras were generally all oriented on the same side of the track. One of the reasons is that the SfM results are much better when one side at a time is processed rather than both sides together. We found that the best cameras orientations to cover the larger area of the slope were to have two cameras oriented at $45^{\circ}$ with the slope that were located at the vehicle front and back (Figure 1, with cameras positioned in the front and in the back of the vehicle). The two other cameras were oriented with different azimuth angles to capture $180^{\circ}$ of the scene, with the maximum overlap (Figure 2D).

The higher the vehicle velocity, the more the cameras positioned opposite to the slope have to be oriented close to the track orientation, to avoid more blurred images and rolling shutter effects. The image quality with the GoPro camera is better at low velocities, such as below $25 \mathrm{~km} / \mathrm{h}$ when acquiring data on a slope located a few metres from the track. It is then better to acquire images at low velocity in one run than at higher velocities in two runs. The best condition to obtain images with an excellent quality occurs on a lightly veiled sunny day with few shadows.

Another element to consider during the image acquisition is the sky visibility for the GNSS chip integrated in the camera. In case the satellite cover is too reduced by the topography (cliffs, canyons, etc.), it is important to have few track sections with sufficient sky views to obtain good image locations used by the processing software to georeference the entire point cloud

During the acquisition, two frames per second were acquired for each of the four cameras. The number of images per kilometre at $20 \mathrm{~km} / \mathrm{h}$ with this configuration is 1440 , which corresponds to 3.8 GB of data (Table 2).

Table 2. Relation between velocity of acquisition, number of images per $\mathrm{km}$ and used memory employing GoPro HERO4 and HERO5.

\begin{tabular}{cccc}
\hline $\begin{array}{c}\text { Velocity of Acquisition } \\
{[\mathbf{k m} / \mathbf{h}]}\end{array}$ & No. Images per $\mathbf{k m}^{\mathbf{1}}$ & $\begin{array}{c}\text { No. Gigabytes per km } \\
\text { [GB] }\end{array}$ & $\begin{array}{c}\text { No. of Covered km per } \\
\text { Full 64 GB Memory } \\
\text { Card }^{\mathbf{2}} \text { [km] }^{\text {[km }}\end{array}$ \\
\hline 5 & 5760 & 15.4 & 17 \\
10 & 2880 & 7.7 & 33 \\
20 & 1440 & 3.8 & 67 \\
30 & 930 & 2.6 & 100 \\
40 & 720 & 1.9 & 133 \\
50 & 576 & 1.5 & 167 \\
\hline
\end{tabular}

${ }^{1}$ With 8 images per second (4 cameras with 2 images per second). ${ }^{2}$ Number of kilometres until each of the 64 GB microSD cards mounted on each camera is full. $64 \mathrm{~GB}$ represents 24,000 images.

\subsection{Image Processing}

We used the Agisoft PhotoScan (Agisoft LLC: St. Petersburg, Russia) [50] photogrammetric processing software that is commonly used in the geosciences [26]. In the camera calibration windows, images are split according to each camera, which are pre-calibrated using files imported from Agisoft Lens software with images of a chessboard. The SfM processing comprises four steps: (1) aligning images; (2) optimization alignment including a rolling shutter correction; (3) creation of a dense cloud that is usually based on a medium quality and a disabled depth filtering; (4) exporting the coordinates of points with their normal and colours from the dense cloud in TXT format. The report generated by the software allows accessing all the camera specifications including the camera location errors. The indicative processing time is given Table 3 . The number of images per processing ranges from 50 to 1700 , according to the scene and platform configuration (a low image number by a high velocity platform (as in a plane) and vice versa. The average number of images processed was approximately 300 images at one time. 
Table 3. SfM processing time using Agisoft PhotoScan photogrammetric software.

\begin{tabular}{ccc}
\hline No. of Images & Processing Time $^{\mathbf{1}}$ & Length of the Modelled Section $^{\mathbf{2}}[\mathbf{m}]$ \\
\hline 100 & $2 \mathrm{~h}$ & 35 \\
200 & $18 \mathrm{~h}$ & 70 \\
300 & 1.4 day & 105 \\
400 & 2.1 day & 140 \\
500 & 2.8 day & 175
\end{tabular}

${ }^{1}$ Average processing time of images using the Agisoft PhotoScan software on a computer with 12 Intel R processors, $6850 \mathrm{~K}$ and $3.6 \mathrm{GHz}$ and an NVIDIA GeForce GTX 1080 (Nvidia Corporation, Santa Clara, U.S.). The parameters in the software were: the highest accuracy for image alignment and a medium quality for dense cloud construction.

${ }^{2}$ With 8 images per second (4 cameras with 2 images per second) and a velocity of $10 \mathrm{~km} / \mathrm{h}$.

\subsection{Georeferencing}

Ground control points (GCP) are commonly used to link the SfM point cloud to real coordinate systems $[20,26]$. Another possibility is to use image coordinates taken from the UAV RTK-GNSS sensor, providing centimetric to decimetric coordinate accuracy [42]. RTK-GNSS stands for "real-time kinematic" which is a GNSS positioning technique using a base and a rover allowing to obtain real-time localisations with an accuracy of few centimetres to one decimetre. However, relative georeferencing and scaling are in most cases sufficient for the majority of geoscience studies because many of the applications are linked to comparisons between point clouds of different periods. The use of GCP or RTK-GNSS for georeferencing requires more costly devices and is more time consuming. Georeferencing 3D point clouds produced by SfM-EV based on two GoPro Hero5 cameras, both of which integrated a GNSS chip, provides point clouds with an absolute positioning on the order of a few metres in planimetry and in altimetry. With the implemented camera system, SfM processing in Agisoft Photoscan with 360 images (equivalent to 1.5 minutes of field acquisition with four cameras with $2 \mathrm{fps}$ ) contains 180 georeferenced images (only two cameras (GoPro Hero5) have a GNSS chip). GNSS chips integrated in the GoPro Hero5 cameras do not use SBAS (satellite-based augmentation systems) services as EGNOS or WAAS that can provide significant corrections of the satellite signals and thus improving the accuracy of the geolocalization.

\subsection{Study Areas}

SfM-EV was tested on several sites in Switzerland in different acquisition settings, throughout the year and at any time of the day. Thus, cameras were held by hand while walking or biking and were mounted on a car, funicular, train, boat, helicopter and plane with different velocities ranging from a few $\mathrm{km} / \mathrm{h}$ to a few hundred $\mathrm{km} / \mathrm{h}$. Most acquisitions were performed using a mast placed on a car. Different environments were imaged, such as a plain with a forest, mountain sides, valleys, flat land, gorges and so on, from altitudes that varied from $0 \mathrm{~m}$ a.s.l. to $2000 \mathrm{~m}$ a.s.l. The specifications of the studied sites are presented in Table 4. 
Table 4. SfM processing time using Agisoft PhotoScan software.

\begin{tabular}{|c|c|c|c|c|c|c|c|c|c|c|}
\hline Study Site & Country & Canton & $\begin{array}{l}\text { Support } \\
\text { Type }\end{array}$ & $\begin{array}{l}\text { No. of } \\
\text { Image }\end{array}$ & $\begin{array}{c}\text { Acquisition } \\
\text { Velocity } \\
{[\mathrm{km} / \mathrm{h}]}\end{array}$ & $\begin{array}{l}\text { Acquisition } \\
\text { Distance } \\
\text { [m] }\end{array}$ & $\begin{array}{l}\text { Coupling/Comparison } \\
\text { other Techniques * }\end{array}$ & Topography & Natural Hazard & Track Type \\
\hline Agites & Switzerland & Vaud & Car & 233 & $5-15$ & 3 & $\begin{array}{l}\text { UAV, MLS, TLS, } \\
\text { HMLS, ALS, STS }\end{array}$ & Cliff & Rockfall & Minor \\
\hline Avants & Switzerland & Vaud & Funicular & 341 & 6 & $5-75$ & No & Grassy slope & Shallow landslide & Minor \\
\hline Bernex & Switzerland & Geneva & Foot & 1710 & 5 & 5 & No & Forest edge & Falling tree & - \\
\hline Bondo & Switzerland & Grisons & Helicopter & 171 & 90 & 350 & No & Valley & Rockfall, debris flow & Minor \\
\hline Dieppe & France & - & Boat & 67 & 6 & 400 & MLS & Cliff & Rockfall & - \\
\hline Dorigny & Switzerland & Vaud & Foot & 350 & 4 & 10 & No & Forest edge & Falling tree & - \\
\hline Les Forges & Switzerland & Jura & Car & 413 & 22 & 50 & UAV & Cliff & Rockfall & Middle \\
\hline Geneva & Switzerland & Geneva & Plane & 55 & 320 & 500 & No & Land & - & - \\
\hline Glion & Switzerland & Vaud & Train & 559 & 15 & 20 & No & Urban slope & Flood & Minor \\
\hline Lausanne & Switzerland & Vaud & Bike & 360 & 7 & 50 & No & Urban & Rockfall, flood & Major \\
\hline Montbovon & Switzerland & Fribourg & Train & 680 & 55 & 6 & No & Slope & Rockfall, landslide & Minor \\
\hline Pichoux & Switzerland & Bern & Car & 374 & $10-15$ & 5 & UAV, HMLS & Gorges, cliff & Rockfall & Minor \\
\hline Salève & France & - & Plane & 56 & 950 & 8000 & No & Mountain & Rockfall & - \\
\hline S-Charl & Switzerland & Grisons & Car & 609 & $5-15$ & 5 & UAV, HMLS & Cliff, forest & Debris flows & Minor \\
\hline Sciernes & Switzerland & Fribourg & Train & 807 & 55 & 6 & No & Valley slope & Rockfall, landslide & Minor \\
\hline Seillon & Switzerland & Neuchâtel & Car & 230 & 50 & 12 & No & Cliff & Rockfall & Highway \\
\hline Territet & Switzerland & Vaud & Funicular & 168 & 9 & 4 & No & Urban slope & Falling tree, rockfall & Minor \\
\hline Verboix & Switzerland & Geneva & Plane & 90 & 350 & 800 & No & Land & Flood & - \\
\hline Weisstannen & Switzerland & St-Gallen & Car & 240 & 20 & 10 & No & Slope, river & Debris flow & Minor \\
\hline
\end{tabular}

(

Total Station, TLS: Terrestrial Laser Scanning. 


\subsection{Sensor Specifications}

The results from SfM-EV were compared with six other remote sensing sensors that can be classified into two classes: moving sensors and static ones. Five sensors belong to the first class: SfM-EV, UAV-based SfM, mobile laser scanning (MLS), also named mobile LiDAR, handheld mobile laser scanning (HMLS), also named handheld LiDAR and aerial laser scanning from the canton of Vaud (ALS-VD) [51], while three sensors belong to the second class: scanning total station (STS), terrestrial laser scanning (TLS) or LiDAR and long range TLS (LRTLS). Brands, models and some features of the used sensors (Figure 3 ) are described in Table 5.

The reference point cloud (RPC) of the comparison was chosen as the Trimble SX10 STS because it is the most accurate of the tested sensors (3D position accuracy of $0.15 \mathrm{~mm}$ at $6 \mathrm{~m}$ ).

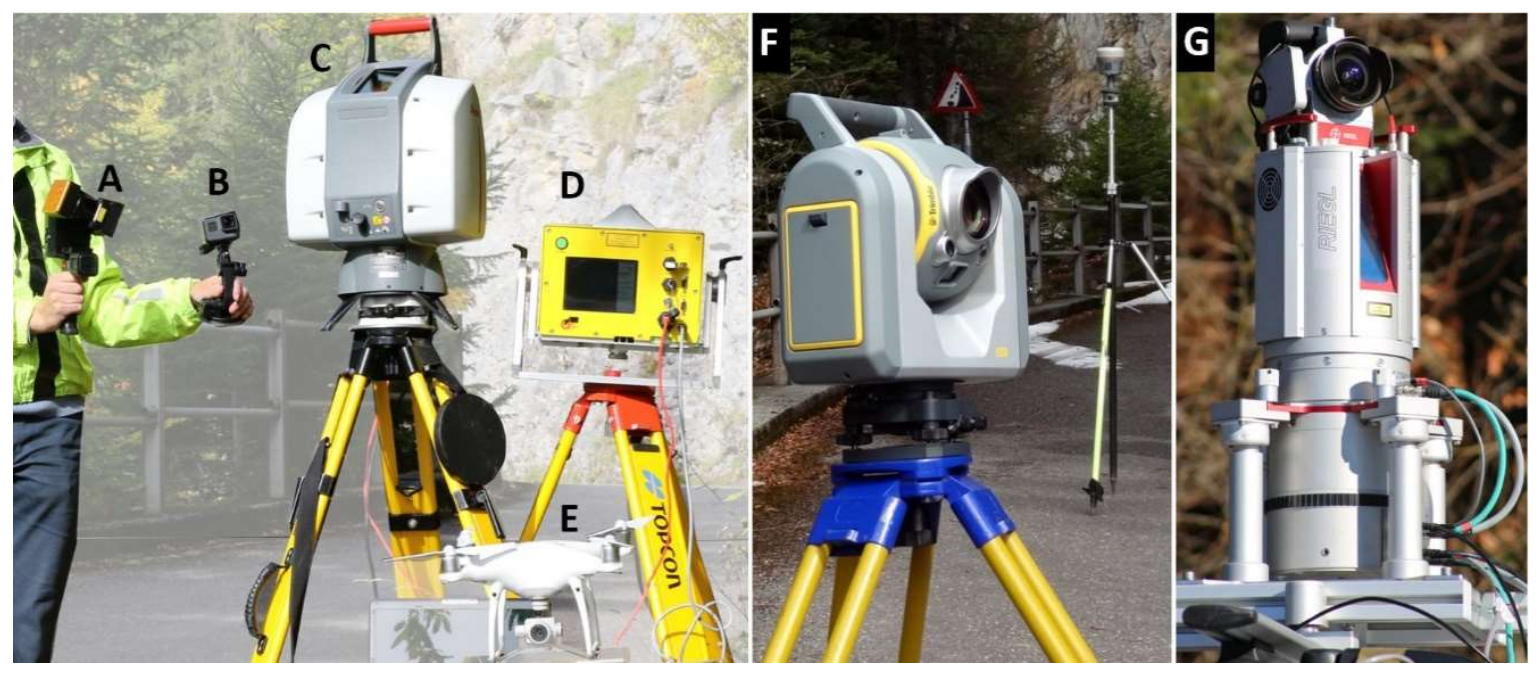

Figure 3. The seven sensors tested: A: HMLS (GeoSLAM ZEB-REVO); B: SfM-EV (GoPro Hero5); C: TLS (Leica ScanStation 2); D: LRTLS (Optech ILRIS-3D); E: UAV-based SfM (DJI Phantom 4 Pro +); F: STS (Trimble SX10, with the corresponding GNSS system, in back, used for the georeferencing); G: MLS (RIEGL VMZ). 
Table 5. Features of the remote sensing sensors used in this study.

\begin{tabular}{|c|c|c|c|c|c|c|c|c|}
\hline Sensors Class & Sensors Type & Brand & Model & Price * & Range [m] & Precision $[\mathrm{cm}]$ & $\begin{array}{l}\text { Average Acquisition } \\
\text { Velocity }[\mathrm{m} / \mathrm{h}]^{* *}\end{array}$ & Reference \\
\hline Moving & SfM-EV & GoPro & HERO4 and HERO5 & 2000 & 25 & 5 & 10,000 & {$[48,49]$} \\
\hline Moving & UAV-based SfM & DJI & Phantom 4 Pro + & 2500 & 50 & 10 & 5000 & {$[52]$} \\
\hline Moving & MLS & RIEGL & VMZ & 300,000 & 800 & 2.5 & 15,000 & [53] \\
\hline Moving & HMLS & GeoSLAM & ZEB-REVO & 50,000 & 10 & 2.5 & 1500 & [54] \\
\hline Moving & ALS-VD & - & - & $10 / \mathrm{km}^{2}$ & - & 15 & 100,000 & [51] \\
\hline Static & STS & Trimble & SX10 & 70,000 & 600 & $<0.5$ & 200 & [55] \\
\hline Static & TLS & Leica & ScanStation 2 & 150,000 & 300 & 0.5 & 100 & [56] \\
\hline Static & LRTLS & Optech & ILRIS-3D & 100,000 & 1500 & 0.5 & 100 & - \\
\hline
\end{tabular}

* Order of magnitude, Euro, hardware and software. ${ }^{* *}$ Length, in metres of the acquisition along the transportation track that can be carried out in one hour. Acronyms: SfM-EV: structure from motion embarked on a vehicle; UAV: unmanned aerial vehicle; MLS: mobile laser scanning; MLS: handheld mobile laser scanning; ALS-VD: aerial laser scanning from the canton of Vaud; STS: scanning total station, TLS: terrestrial laser scanning; LRTLS: long range terrestrial laser scanning. 


\subsection{Accuracy and Precision Calculation}

As a reminder, accuracy is distance between true values and measurements, while precision is a measure of the spread of the measurements. In our case, accuracy is similar to the error of georeferencing. SfM-EV precisions (see Section 3.1) that depended on the distance of acquisition and the velocity of acquisition were evaluated on twelve objects: five cardboard boxes with volumes ranging from $1 \mathrm{dm}^{3}$ to $150 \mathrm{dm}^{3}$, five spheres with a diameter of approximately $25 \mathrm{~cm}$ made of different materials (rusted iron, aluminium, black tape, unpolished and polished terracotta), one $50 \times 50 \mathrm{~cm}$ square target and one $1 \mathrm{~m}$ ruler. Two analyses were carried out. The first one focused on the length of the reconstructed elements compared to the true lengths $\left(\mathrm{L}_{\mathrm{t}}\right)$, measured in the field with a ruler. $L_{t}$ values were compared to measured lengths $\left(L_{m}\right)$ on the point clouds by constructing the ratio $\left(\mathrm{L}_{\mathrm{t}}-\mathrm{L}_{\mathrm{m}}\right) / \mathrm{L}_{\mathrm{t}}$. The measured lengths are the three axes on the cardboard boxes (i.e., the three perpendicular edges), the diameter for the spheres and the target and ruler lengths. The second analysis concerns the precision of the planes on the faces of the cardboard boxes by fitting planes. The standard deviations are the results of the difference between the three fitted planes and the corresponding cardboard faces. Tests with different velocities were carried out with a $10 \mathrm{~m}$ acquisition distance and tests with distance variation were carried out with a $5 \mathrm{~km} / \mathrm{h}$ acquisition velocity. The pixel sizes were measured directly, after a high zoom, on the images because of the presence of the ruler and the target on the pictures.

To analyse the georeferencing (accuracy) of SfM-EV point clouds (see Section 3.2), they were transformed into the Swiss coordinates. We compared the obtained coordinates with the true coordinates extracted from orthorectified aerial images from swisstopo in a GIS (geographic information system) or from the Swiss geoportal [57]. The precisions of the 3D point clouds of the eight tested sensors (see Section 3.4.1) were calculated after performing the best possible manual alignment between RPC and the other clouds. A comparison was made using point-to-mesh strategy in CloudCompare [58]. A mesh was generated from the RPC and then the other point clouds were compared to this referenced mesh to obtain the standard deviation (SD).

The accuracies of the automatic georeferenced 3D point clouds from the STS, ALS, MLS, SfM-EV and UAV-based SfM sensors (see Section 3.4.2) were calculated measuring the length of the 3D vectors' shifts between the RPC and the compared clouds. The accuracies correspond to the root mean square (RMS) of the $\mathrm{X}, \mathrm{Y}$ and $\mathrm{Z}$ shifts. For each cloud, shifts of approximately ten points distributed in the entire cloud were measured and their average is the accuracy value of the cloud.

The densities of points on a $15 \mathrm{~m}$ height cliff of the different 3D point clouds were calculated using the "point density" function in the CloudCompare software enabled by the "surface density" option. The precision SDs were also obtained in CloudCompare by fitting a statistical model on the measured distances calculated using the "cloud/mesh distances" function. Since the densities of points on a wide area for clouds from static sensors (STS, TLS and LRTLS) differ significantly because of the high distance of the cliff-sensor variations ( $2 \mathrm{~m}$ to $30 \mathrm{~m}$ ), the densities of points from static sensors were then calculated by the average of the density of points on the entire cliff.

\section{Results}

\subsection{Precision}

We tested SfM-EV based on GoPro HERO4 and HERO5 on a wide parking area by varying the car velocity and the acquisition distance. Acquisition distances varied from 1, 5, 10 and $15 \mathrm{~m}$, to $50 \mathrm{~m}$ and velocities ranging from $5 \mathrm{~km} / \mathrm{h}$ to $40 \mathrm{~km} / \mathrm{h}$ with $5 \mathrm{~km} / \mathrm{h}$ steps. However, not all combinations were explored because some did not provide any relevant results, or at more than $20 \mathrm{~m}$, the used velocities were only 5 and $10 \mathrm{~km} / \mathrm{h}$ because of ditches limiting the car velocity. Tests were carried out during mid-October 2017 by sunset at the end of a sunny afternoon. The study area had sunlight exposure at the beginning of the test and then had shadow exposure for the tests that occurred during acquisition 
distances from 25 to $50 \mathrm{~m}$. The results with a variation of the acquisition distances are presented in Figure 4 and the results with a variation of the velocity are shown in Figure 5.

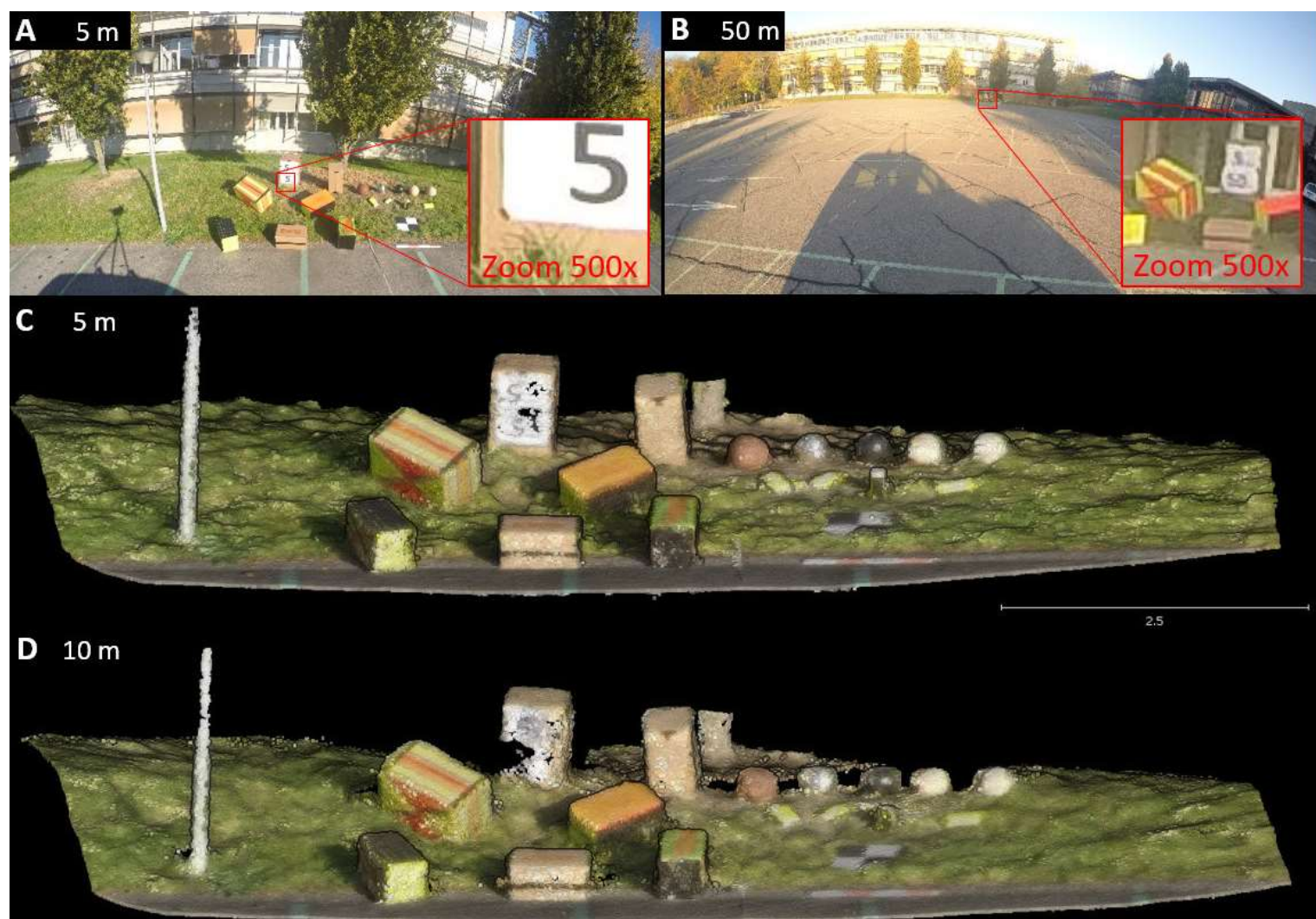

E $25 \mathrm{~m}$

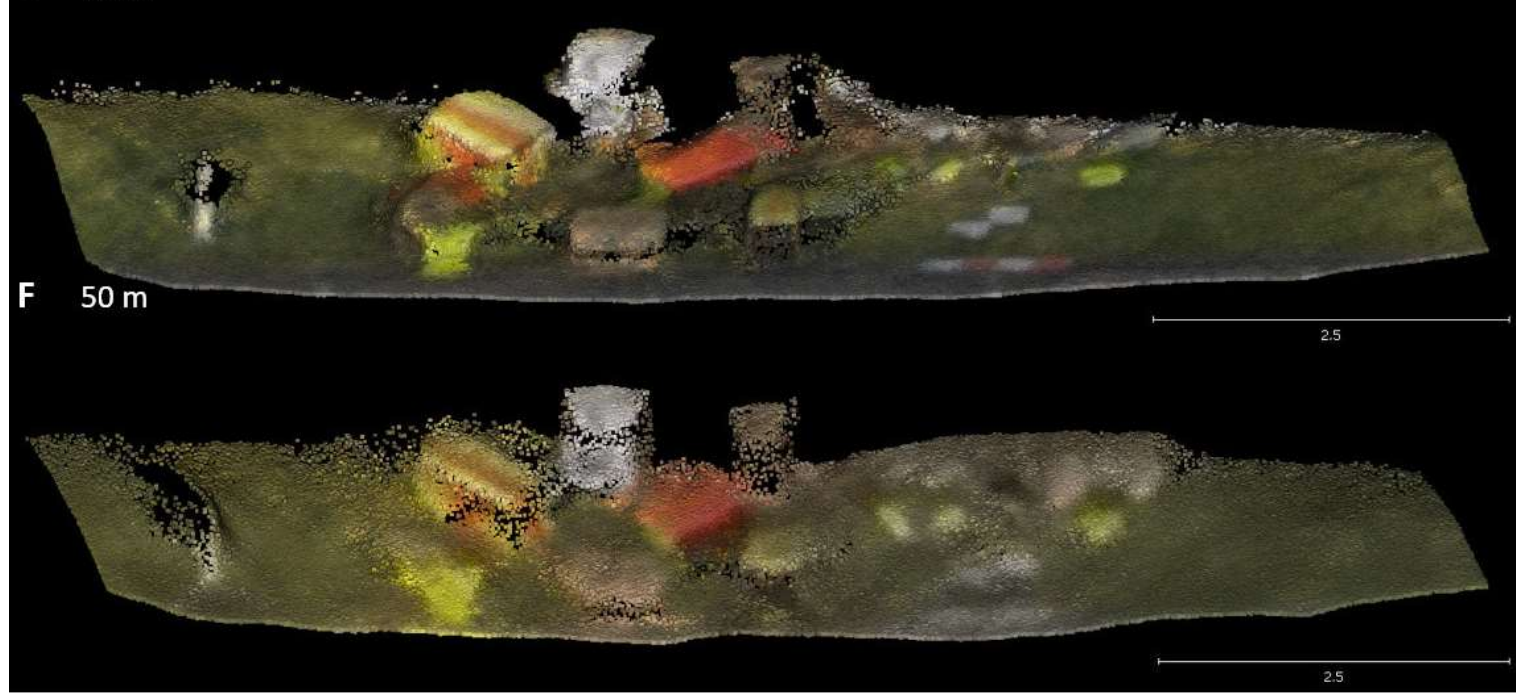

Figure 4. Influence of the distance of acquisition on the SfM-EV results. Processed images (A,B) were taken with a velocity of acquisition of $5 \mathrm{~km} / \mathrm{h}$ with a distance acquisition of $5 \mathrm{~m}(\mathbf{C}), 10 \mathrm{~m}(\mathbf{D}), 25 \mathrm{~m}(\mathbf{E})$ and $50 \mathrm{~m}(\mathbf{F})$.

The results of the differences in lengths of the objects' edges show that the precision of the twelve evaluated elements decreases notably above the acquisition velocity of $25 \mathrm{~km} / \mathrm{h}$ and with an acquisition distance greater than $15 \mathrm{~m}$ (Figure 6). The optimal ratio to guarantee both the highest velocity and distance acquisition while maximizing the precision is at velocity of $25 \mathrm{~km} / \mathrm{h}$ and at 
a distance of acquisition of $15 \mathrm{~m}$. For acquisition velocities lower than $15 \mathrm{~km} / \mathrm{h}$, we obtain a $<1 \mathrm{~cm}$ difference between $\mathrm{L}_{t}$ and $\mathrm{L}_{\mathrm{m}}$. For acquisition distances lower than $15 \mathrm{~m}$, the obtained difference between $\mathrm{L}_{t}$ and $\mathrm{L}_{\mathrm{m}}$ is $1.1 \mathrm{~cm}$. The differences increase strongly at a distance acquisition of $20 \mathrm{~m}$, reaching $10.1 \mathrm{~cm}$ at $50 \mathrm{~m}$. Above $25 \mathrm{~m}$, the object models are smoothed, and the technique no longer correctly represented the objects (Figure 4E). The SD obtained from the difference between the fitted planes on the cardboard boxes' faces indicate that the SD also increases considerably above a velocity of $25 \mathrm{~km} / \mathrm{h}$ (Figure 7) while the SD increases linearly with the increase of the distance.

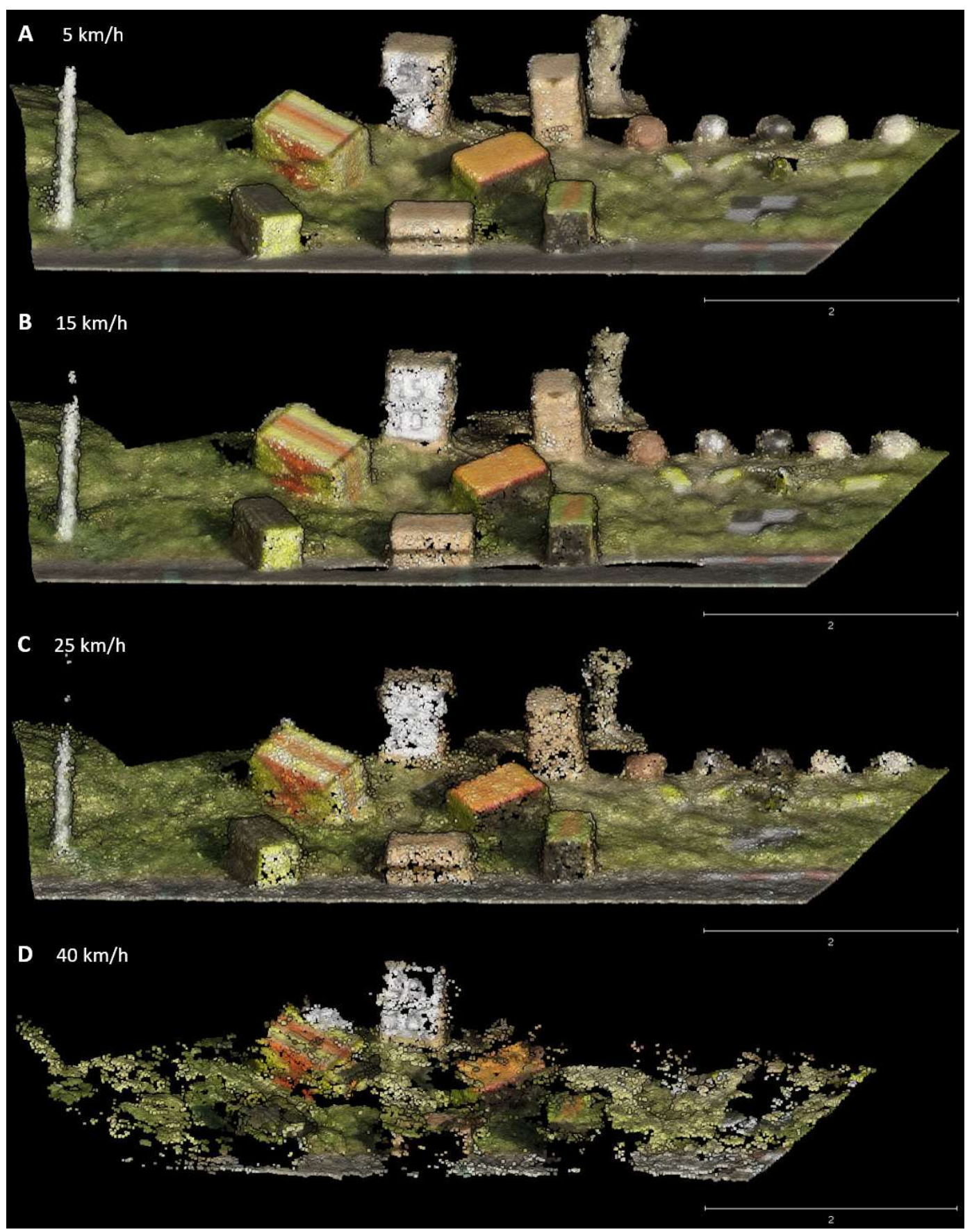

Figure 5. Influence of the velocity of acquisition on SfM-EV SfM results. Processed images were taken with a distance of acquisition of $10 \mathrm{~m}$ with a velocity of acquisition of $5 \mathrm{~km} / \mathrm{h}(\mathbf{A}), 15 \mathrm{~km} / \mathrm{h}$ (B), $25 \mathrm{~km} / \mathrm{h}(\mathrm{C})$ and $40 \mathrm{~km} / \mathrm{h}$ (D). The main cause of the degradation of the results with the velocity increase is not the image resolution decrease (for the distance variation) but rather the decrease of the image number (102 images processed for $5 \mathrm{~km} / \mathrm{h}, 42$ for $15 \mathrm{~km} / \mathrm{h}, 25$ for $25 \mathrm{~km} / \mathrm{h}$ and 17 for $40 \mathrm{~km} / \mathrm{h}$ ). 


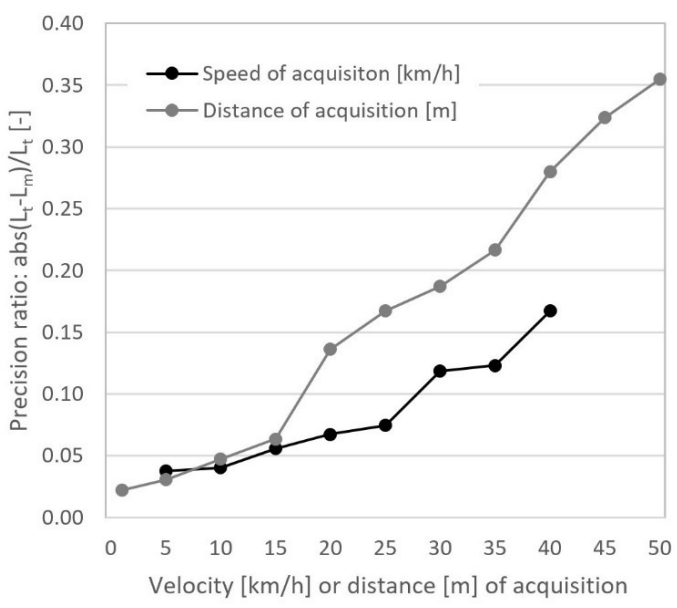

Figure 6. Impact of velocity and distance variations on the precision during images acquisition. Each dot represents the average precision measured on 12 elements ( 5 cardboard boxes, 5 spheres, 1 target and 1 ruler). The precision was calculated with a ratio combining true lengths (measured in the field with a ruler) and measured lengths on the point clouds. The ratio is the absolute value of the difference between the true length $\left(\mathrm{L}_{t}\right)$ and the measured length $\left(\mathrm{L}_{\mathrm{m}}\right)$ over the true length: abs $\left(\mathrm{L}_{t}-\mathrm{L}_{\mathrm{m}}\right) / \mathrm{L}_{\mathrm{t}}$. The measured lengths are the three axes on the cardboard boxes (i.e., the three perpendicular edges), the diameter for the spheres and the target and ruler lengths.

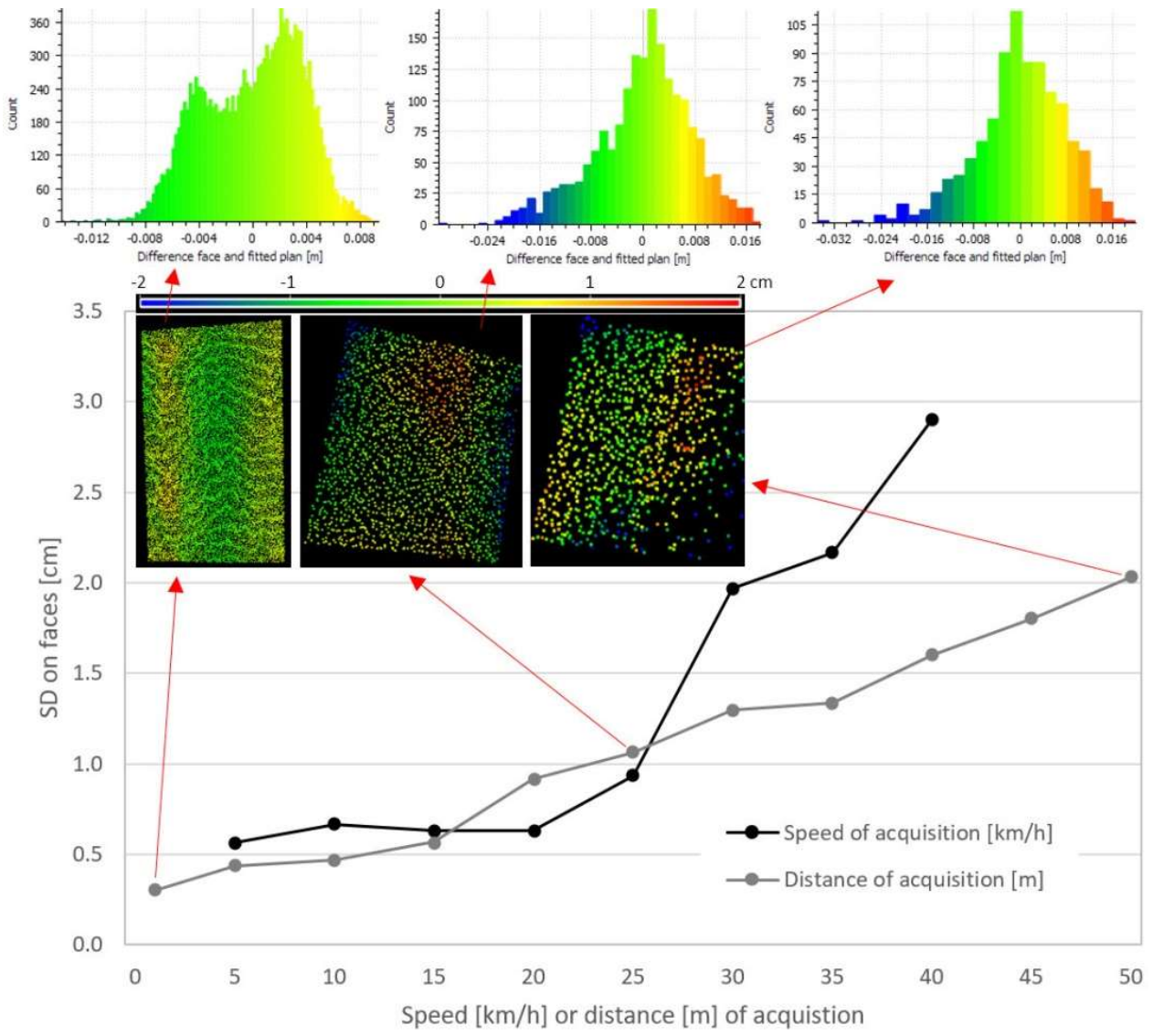

Figure 7. Impact of velocity and distance variations on the precision during image acquisitions. Each dot represents the average precision measured on three faces with different orientations of three different cardboard boxes. A plane was fitted on each face in CloudCompare and the resulting standard deviation between the fitted planes and the cardboard box faces yields the precision. For distance acquisitions of 1, 25 and $50 \mathrm{~m}$, the differences of distances on the point clouds as well as the corresponding histograms are shown. 


\subsection{Automatic Georeferencing}

Degradations of the GNSS signals according to the camera velocity and the sky obstruction due to the vehicle and/or natural elements, such as a cliff or trees above the track, were classified into six classes with an indicator. The GNSS signal degradation indicator (GNSS SDI) ranges from the level 0 , which indicates no sky obstruction with a sensor velocity below $30 \mathrm{~km} / \mathrm{h}$, to the level 6 , which shows a full sky obstruction, for example, in a tunnel, or a very high sky obstruction with a sensor velocity of a few hundreds of kilometres per hour, similar to the sensor being mounted on a plane body behind a porthole. If the first sky obstruction, level 0, was not met during all of the 29 tests, we had 5 sky obstructions of level 1,9 of level 2, 4 of level 3, 3 of level 4, 3 of level 5 and one of level 6 (Table 6). The test results indicate that we can expect an accuracy of the XYZ positioning of the whole point cloud at $5 \mathrm{~m}$ for a very low sky obstruction, $10 \mathrm{~m}$ for a low sky obstruction, $25 \mathrm{~m}$ for a middle sky obstruction, $50 \mathrm{~m}$ for a high sky obstruction and $150 \mathrm{~m}$ for a very high sky obstruction (Figure 8). Considering only the planimetric accuracy, a $2 \mathrm{~m}$ accuracy is expected for a very low sky obstruction, $5 \mathrm{~m}$ with a low, $10 \mathrm{~m}$ with a middle, $25 \mathrm{~m}$ with a high and $125 \mathrm{~m}$ with a very high sky obstruction. The values for the altimetric accuracy are approximately 1.5 times the planimetric one. The full sky obstruction does not allow obtaining an automatic georeferencing.

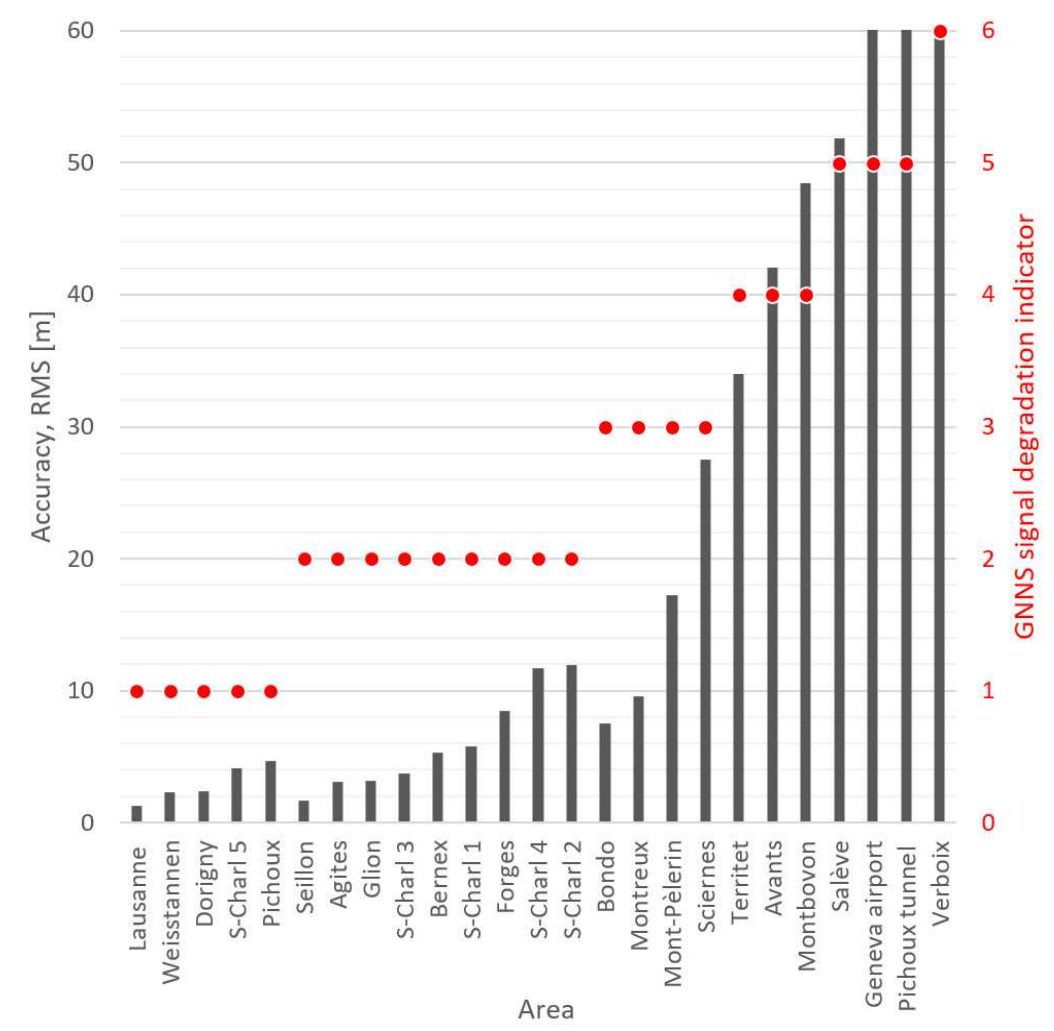

Figure 8. Accuracies, indicated by the RMS of the $X, Y$ and Z shifts, with the GNSS signal degradation indicator of 25 study sites. 
Table 6. Accuracies according to GNSS signal degradation indicator (GNSS SDI).

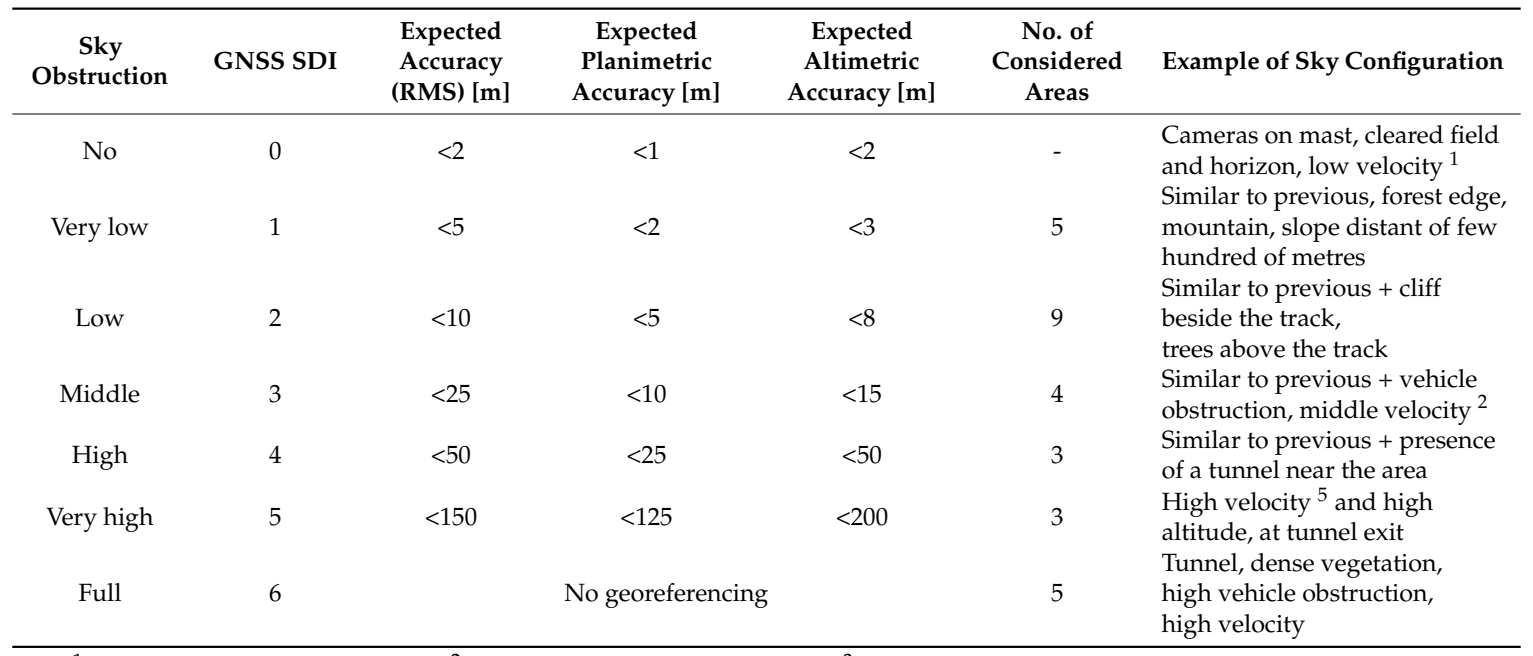

${ }^{1}$ Velocity lower than $30 \mathrm{~km} / \mathrm{h} .{ }^{2}$ Velocity lower than $120 \mathrm{~km} / \mathrm{h} .{ }^{3} 129 \mathrm{~m}$ removing one result where the altitude was incorrectly evaluated (1200 m of elevation error) during a plane flight. ${ }^{4} 180.3 \mathrm{~m}$ removing one result where the altitude was incorrectly evaluated (1200 $\mathrm{m}$ of elevation error) during a plane flight. ${ }^{5}$ Plane flight velocity.

\subsection{Image Resolution and Overlap}

For field acquisitions in the geosciences, the speed of the platform (car, train, etc.) and the distance of the acquisition are the two main factors controlling the quality of the results but they are often imposed by the local conditions. From an SfM point of view, the quality of the results depends on the resolution, the overlap ratio and the image quality (contrast and sharpness). The image resolution directly depends on the distance of the acquisition and the overlaps directly on the speed of the platform and the frequency of the acquisition (fixed to 2 images/second for the GoPro cameras used here). On the transportation tracks, only the vehicle speed and thus the overlap, can be chosen since the acquisition distance and hence the image resolution, is given by the topographical configuration.

With the used cameras, the GSD (ground simple distance) of the pixel is $4.5 \mathrm{~cm}$ at a distance of $5 \mathrm{~m}, 7 \mathrm{~cm}$ at $10 \mathrm{~m}, 9.5 \mathrm{~cm}$ at $15 \mathrm{~m}, 14.5 \mathrm{~cm}$ at $25 \mathrm{~m}$ and $27 \mathrm{~cm}$ at $50 \mathrm{~m}$ (Figure 9A). GSDs were estimated during tests on the parking area by varying the acquisition distance from 1 to $50 \mathrm{~m}$. The overlap depends on the number and the orientations of cameras. The standard configuration to survey roadsides is four cameras mounted on a mast placed on a vehicle roof. One camera is oriented forward, one backward and two cameras are oriented perpendicularly to the roads with different tilt angles (Figure 1). As shown in Figure 10A,B, the overlapping ratio between two consecutive pictures from the same camera is high with acquisition velocities below $25 \mathrm{~km} / \mathrm{h}$ and distances of acquisition below $15 \mathrm{~m}$. Thus, there is an overlap of $92 \%$ for a camera oriented perpendicularly with an acquisition velocity of $20 \mathrm{~km} / \mathrm{h}$ and a distance of acquisition of $10 \mathrm{~m}$ (Figure 10A). For a forward or backward camera, the overlap ratio is $82 \%$ for a similar velocity and distance of acquisition (Figure 10B). These overlapping ratios were estimated with trigonometrical calculations. Considering all cameras together, it is better to consider the number of times a point on the ground surface is captured by the cameras. Typically, an object appears on 11 pictures taken from a camera oriented perpendicularly to the track with an acquisition velocity of $20 \mathrm{~km} / \mathrm{h}$ and an acquisition distance of $10 \mathrm{~m}$ (Figure 10C). When the four cameras are considered, an object on the trackside is seen on 38 pictures, for a similar velocity and distance of acquisition (Figure 10D). 


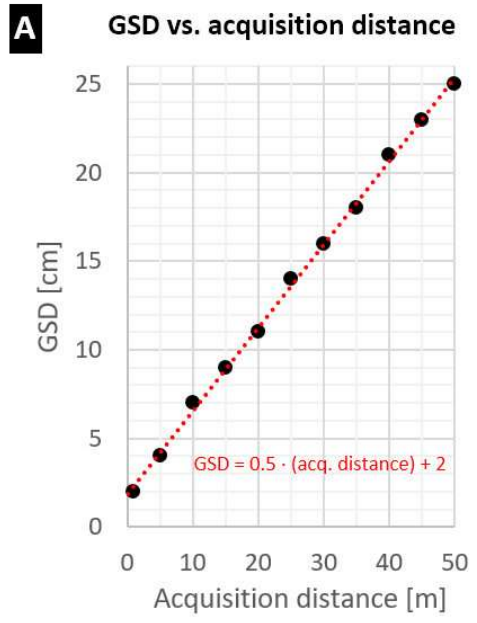

B Point density vs. acquisition distance

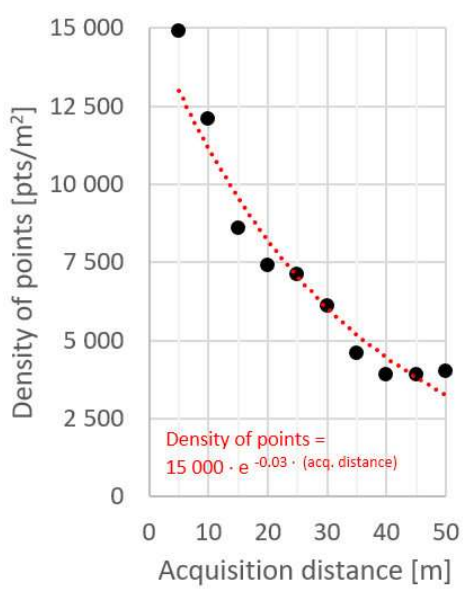

D Point density vs. acquisition velocity

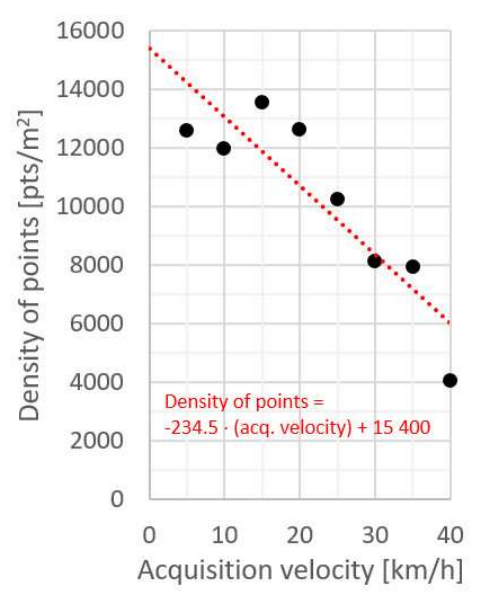

C Precision vs. acquisition distance

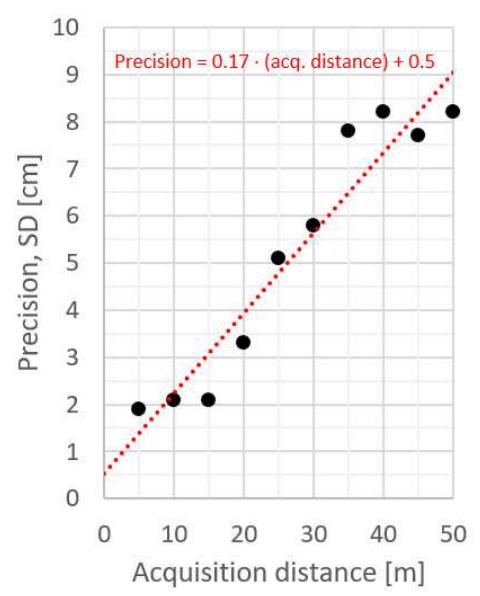

E

Precision vs. acquisition velocity

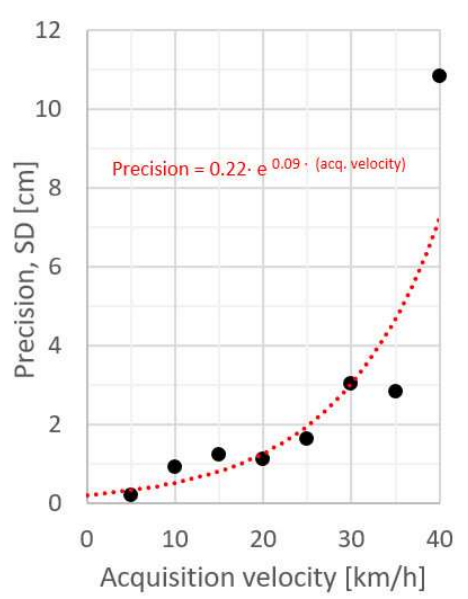

Figure 9. (A): Linear correlation between the acquisition distance and the pixel size on the GoPro images. (B): Negative power law correlation between the acquisition distance and the density of points in the SfM-EV clouds with an acquisition velocity of $5 \mathrm{~km} / \mathrm{h}$. (C): Linear correlation between the acquisition distance and the SD of the precision which was evaluated on the entire point cloud of the test area in the parking area. (D): Negative linear correlation between the acquisition velocity and the density of points in SfM-EV clouds with an acquisition distance of $10 \mathrm{~m}$. (E): Exponential correlation between the acquisition velocity and the SD of the precision. 

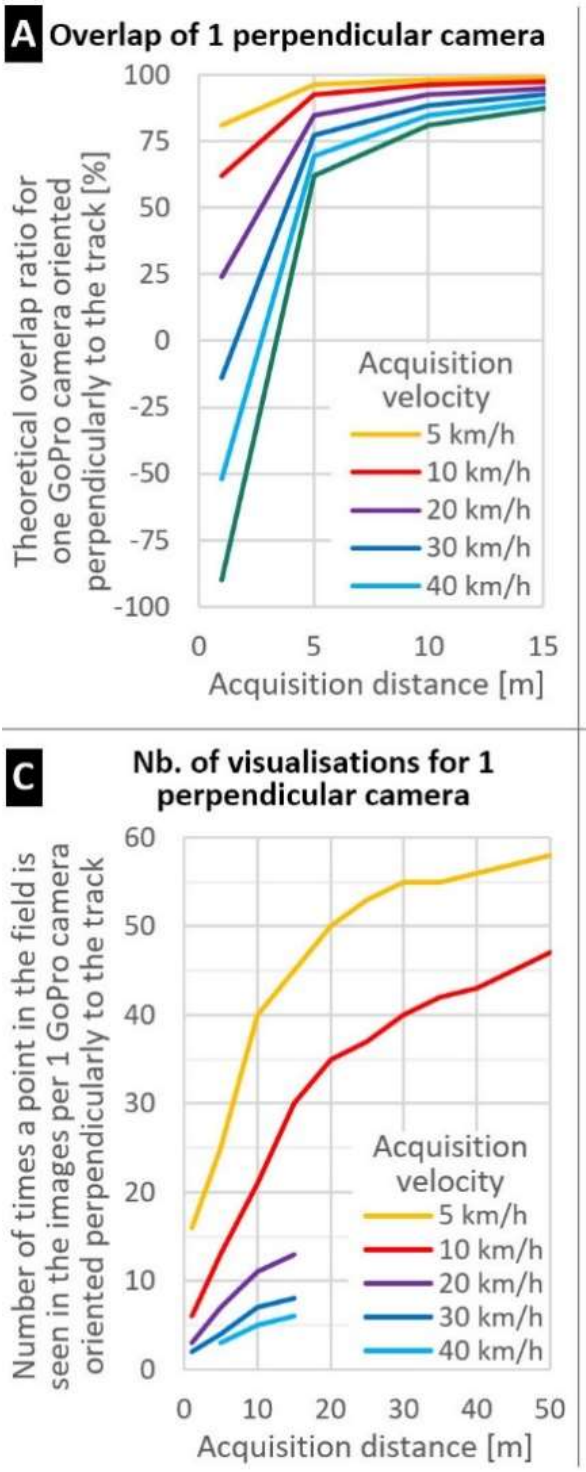

\section{B Overlap of 1 back/forward camera}

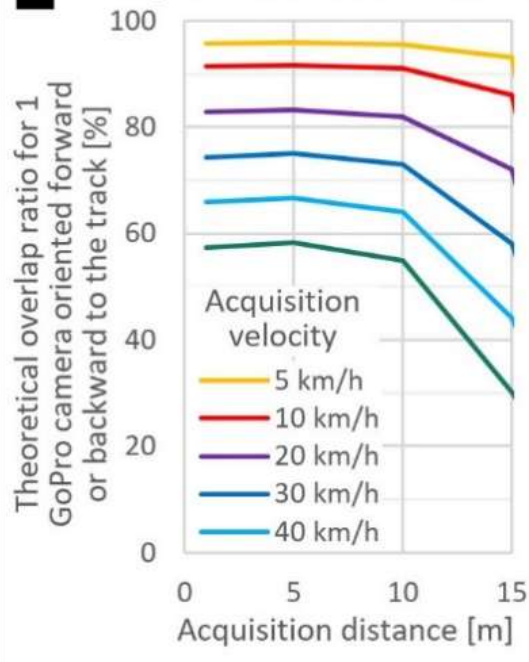

\section{Nb. of views for 4 cameras}

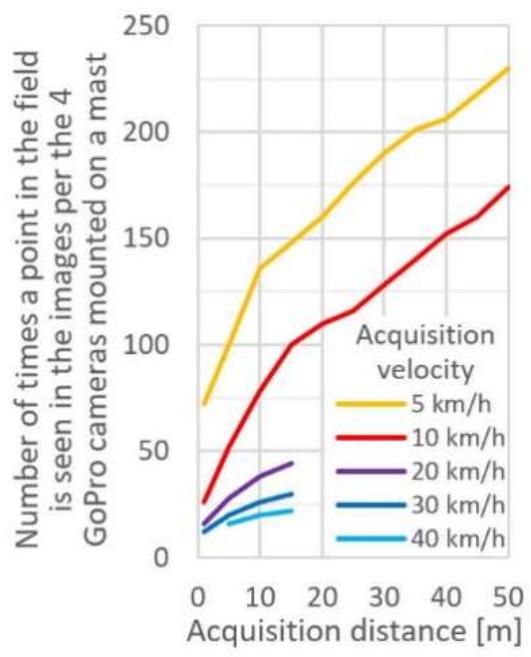

Figure 10. Overlapping ratios with the standard configuration by roadsides survey: four cameras mounted on a mast located on a car roof. One camera is oriented frontward, one backward and two perpendicular to the track. The values in $(\mathbf{A}, \mathbf{B})$ are obtained using trigonometric calculations while the values in $(\mathbf{B}, \mathbf{C})$ were obtained from acquisitions in the field. (A): Theoretical overlap ratio for one GoPro camera oriented perpendicularly to the track path. (B): Theoretical overlap ratio for one GoPro camera oriented forward or backward to the track path. A distance limit of $15 \mathrm{~m}$ the forward or backward direction of the camera is defined for the overlap calculation to set aside pixels with a GSD above $10 \mathrm{~cm}$. (C): Number of times that a point in the field is seen in the images taken by one GoPro camera oriented perpendicularly to the track. (D): Number of times that a point in the field is seen in the images taken by the four GoPro cameras mounted on a mast placed on a roof of a car.

\subsection{Comparison with other Techniques}

SfM-EV was compared with seven other survey techniques on a narrow mountain road where rockfalls threaten to fall from a $15 \mathrm{~m}$ high cliff (Figure 11F). The acquisitions were performed in two days with no rockfall between the two acquisitions dates. Vegetation was removed during the clouds' comparison. 

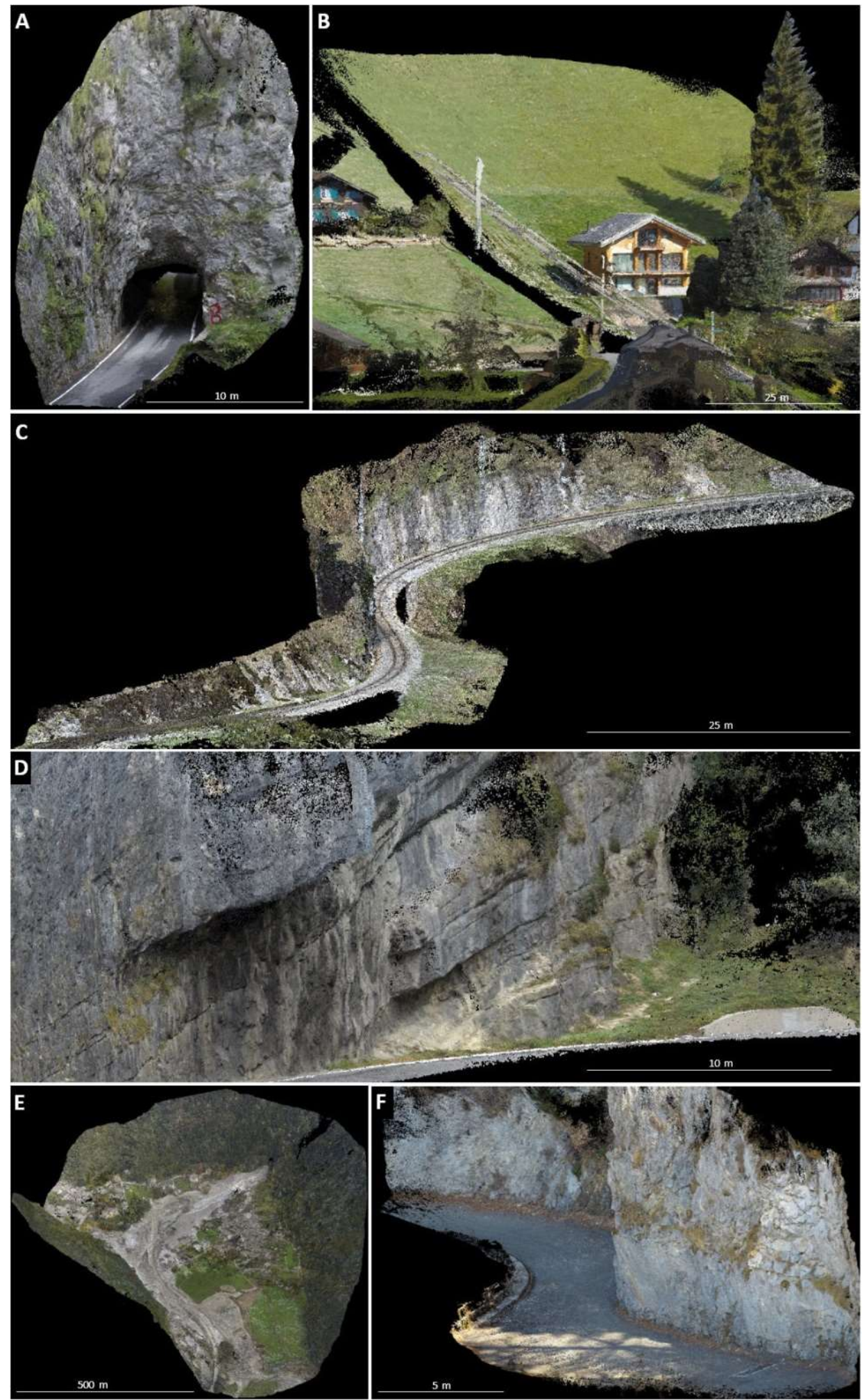

Figure 11. Examples of some of the SfM-EV results in Switzerland in 2017. (A): Tunnel entry in the Pichoux gorges (canton of Bern). Images taken from a car. (B): Chalet in the Avants (canton of Vaud). Images taken from a funicular. (C): Rocky embankment along the train line Montreux-Montbovon (canton of Fribourg). Images taken from a train. (D): Cliff along the motorway in the Seillon gorges (canton of Neuchâtel). Images taken from a car. (E): Village of Bondo (canton of Grisons) after being hit by a debris flow. Images taken from a helicopter. (F): Cliff along the Agites mountain road where eight survey techniques were tested (canton of Vaud). Images taken from a car. 
Moving sensors were at approximately $2 \mathrm{~m}$ from the cliff and static sensors were placed approximately $6 \mathrm{~m}$ from the cliff. The density of points was measured on the $35 \mathrm{~m}$ long and $10 \mathrm{~m}$ high cliff. The ALS-VD point cloud density of points on a flat area was measured at 14 points $/ \mathrm{m}^{2}$ which corresponds to the value given by the ASIT-VD (2017). Two acquisition points were necessary for static sensors to survey the entire cliff. Since the cliff was almost vertical, beams from the ALS-VD fell tangential to the cliff, which provide a point density of $2.5 \mathrm{pts} / \mathrm{m}^{2}$. The UAV-based SfM possessed $1200 \mathrm{pts} / \mathrm{m}^{2}$, the HMLS $4500 \mathrm{pts} / \mathrm{m}^{2}$, the MLS $4800 \mathrm{pts} / \mathrm{m}^{2}$, the SfM-EV 20,500 pts $/ \mathrm{m}^{2}$, the TLS $23,800 \mathrm{pts} / \mathrm{m}^{2}$, the STS $38,500 \mathrm{pts} / \mathrm{m}^{2}$ and the LRTLS $47,500 \mathrm{pts} / \mathrm{m}^{2}$ (Figure $12 \mathrm{~A}$ ). SfM-EV and UAV-based SfM dense cloud processing were carried out with the "middle" densification parameter in the dense cloud quality setting in the Agisoft PhotoScan software. Using the "high" dense cloud parameter in this photogrammetric software increases the SfM-EV density of points to 51,900 points, which increases by 2.5 times the density of points of the SfM cloud.

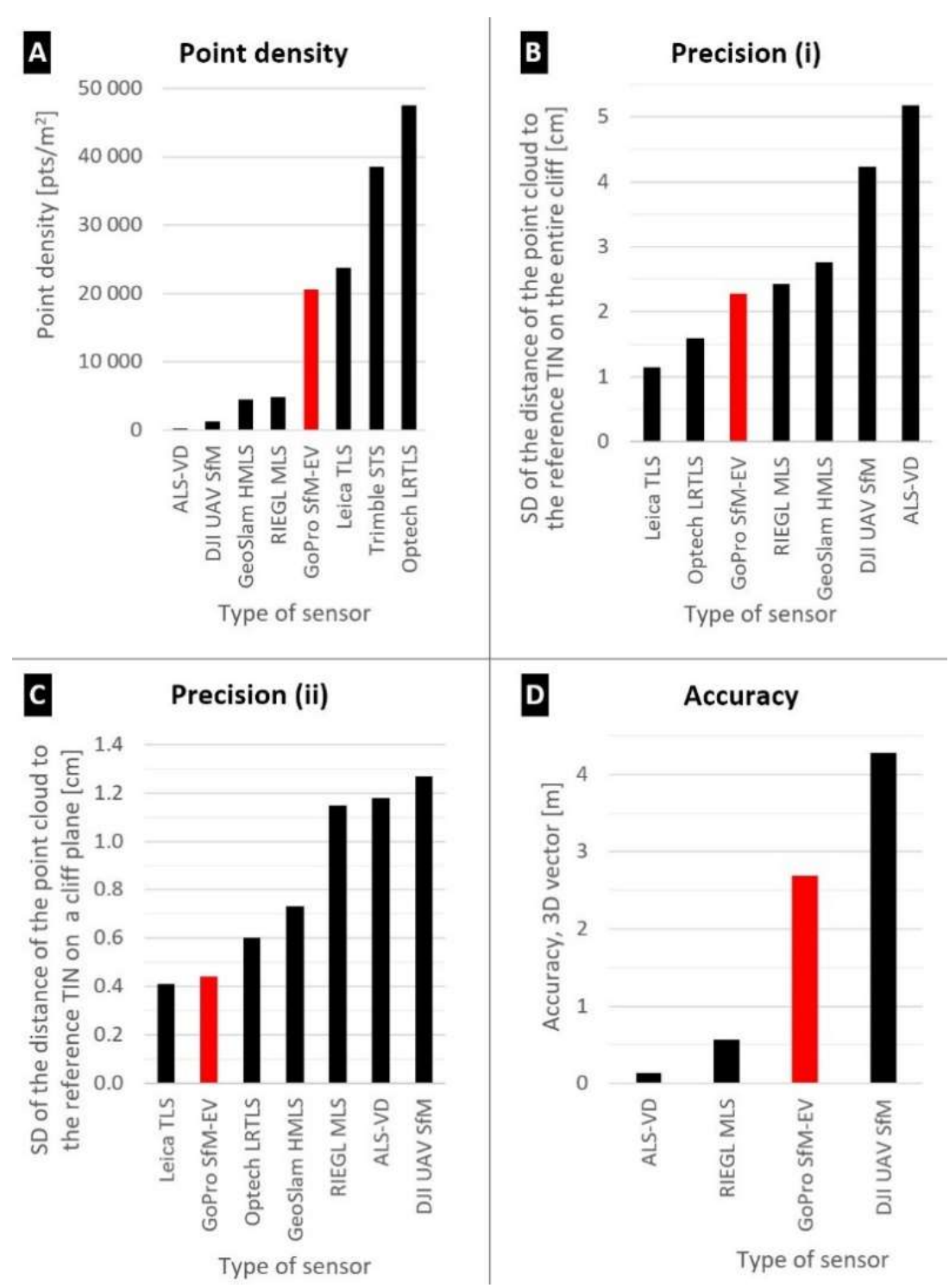

Figure 12. Precision and accuracy results of the comparison of the 3D point clouds of the eight tested remote sensing sensors. The reference point cloud is the Trimble SX10 STS. (A): Comparison of density of points on the $350 \mathrm{~m}^{2}$ cliff. (B): Precision of the seven sensors tested on the entire cliff $\left(350 \mathrm{~m}^{2}\right)$. (C): Precision of the seven sensors tested on a $5 \mathrm{~m}^{2}$ flat cliff part. (D): Accuracy (georeferencing) of the four sensors tested. See Section 2.6 for details about the calculation of the point density, precision and accuracy. See Table 5 for more information about the type of sensors. 
The low density of points of the UAV-based SfM results is explained by the fact that the axes of view of the images from the UAV are quite parallel to the cliff because the UAV flew approximately $25 \mathrm{~m}$ above the track to fly over the trees. Except for the HMLS, the density of points of all techniques can be parameterized to increase them by post-processing with SfM techniques or in the field by choosing the distance between the points for LiDAR sensors.

\subsubsection{Precision}

The precisions of the techniques were evaluated on the entire cliff section of $350 \mathrm{~m}^{2}$ (35 m length and $10 \mathrm{~m}$ height) and on a $5 \mathrm{~m}^{2}(2.5 \times 2.5 \mathrm{~m})$ flat cliff part using the RPC (see Section 2.6)

The precisions on the entire $350 \mathrm{~m}^{2}$ cliff (Figure 12B) were: TLS SD $=1.2 \mathrm{~cm}$, LRTLS SD $=1.6 \mathrm{~cm}$, SfM-EV SD $=2.3 \mathrm{~cm}$, MLS SD $=2.4 \mathrm{~cm}$, HMLS SD $=2.8 \mathrm{~cm}$, UAV-based SfM SD $=4.2 \mathrm{~cm}$ and ALS-VD $\mathrm{SD}=5.2 \mathrm{~cm}$. The precisions on the $5 \mathrm{~m}^{2}$ cliff part (Figure 12C) were: the TLS and SfM-EV SD $=0.4 \mathrm{~cm}$, the LRTS SD $=0.6 \mathrm{~cm}$, HMLS SD $=0.7 \mathrm{~cm}$, MLS SD $=1.2 \mathrm{~cm}$, ALS SD $=1.2 \mathrm{~cm}$ and the UAV-based SfM $\mathrm{SD}=1.3 \mathrm{~cm}$. The ALS-VD result must be taken with caution since there were only 7 points on the flat cliff part in comparison with an average of 203,000 points for the other clouds.

Precision results show, not surprisingly, that the best results are obtained with the static sensors (TLS, LRTLS), followed by the mobile sensors moving on the ground and (SfM-EV, HMLS, MLS) and finally, by the airborne sensors above the track (UAV-based SfM, airborne LiDAR). The precision of SfM-EV is surprisingly within the average, showing its pertinence to survey track sides.

\subsubsection{Automatic Georeferencing}

The automatic georeferencing positioning of the RPC based on the Trimble SX-10 is the best because it could be located using RTK-GNSS. The georeferencing was performed using the virtual reference station service of swipos from swisstopo with a planimetric accuracy of $2 \mathrm{~cm}$ and altimetric accuracy of $4 \mathrm{~cm}$ [59]. Thus, the positioning accuracy results have an SD close to $5 \mathrm{~cm}$.

Georeferencing shifts of the point clouds compared to the RPC (Figure 12D) were $0.1 \mathrm{~m}$ for the ALS-VD, MLS $0.6 \mathrm{~m}$, SfM-EV $2.7 \mathrm{~m}$ and UAV-based SfM $4.3 \mathrm{~m}$. The airborne accuracy shift of $14 \mathrm{~cm}$ lies within the accuracy of $22 \mathrm{~cm}$ provided by ASIT-VD (2017). The positioning for the MLS is larger than the accuracy provided by the manufacturer $(<5 \mathrm{~cm}$, RIEGL, 2017) because the acquisition conditions were not ideal (the straight road around the area was too short to initialize the system, many sky obstructions existed, and the post-processing input data could have been more accurate). SfM-EV and UAV-based SfM are the only two techniques with any RTK-GNSS georeferencing and that use only a (low-cost) GNSS chip without live or post-processing corrections. The more image locations there are, the more constrained the point cloud will be.

\subsection{Examples}

Here, some examples of SfM-EV results on different study sites are presented. Specifications of the study sites are given in Table 4 .

The first example is related to a strong summer storm that occurred in July 2015 in the S-Charl valley in the canton of Grison (Switzerland), producing 16 debris-flows along a $4.5 \mathrm{~km}$ road section. A comparison of two SfM-EV 3D point clouds from images taken a few days before and after the storm from a car shows that the volumes of the different debris-flow deposits on the road sides range from 20 to $6650 \mathrm{~m}^{3}$ for a total of $16,000 \mathrm{~m}^{3}$ (Figure 13). The acquisition velocity was $5 \mathrm{~km} / \mathrm{h}$ and the acquisition distance was $5 \mathrm{~m}$ with the indicator of GNSS signal degradation (GNSS SDI) at 2. 


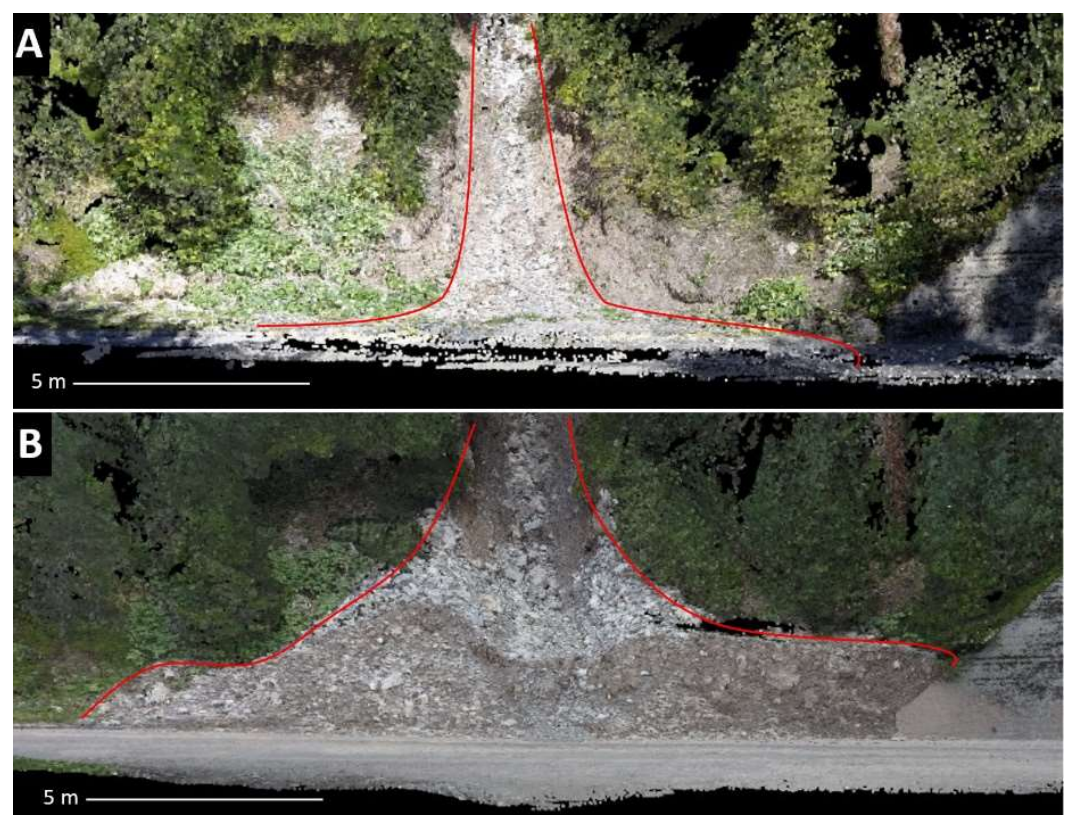

Figure 13. Example of an area affected by a debris flow on July 2016 in S-Charl valley, (Switzerland), with 3D point clouds from SfM-EV taken before (A) and after (B) the event. The deposition volume here was estimated at $90 \mathrm{~m}^{3}$.

The second example consists of 3D point clouds obtained from a car at a velocity of $15 \mathrm{~km} / \mathrm{h}$ from a road passing at the foot of a $60 \mathrm{~m}$ high cliff above a tunnel in the Pichoux gorges, canton of Bern. The results were used as digital elevation model for rockfall simulations (Figure 11A). The acquisition velocity was $15 \mathrm{~km} / \mathrm{h}$ and the acquisition distance was $5 \mathrm{~m}$ with a GNSS SDI of 5 . Acquisitions from trains and funiculars have delivered models of cliffs, engineering infrastructures and the environment around tracks. Figure 11B illustrates a result from images taken from the Les Avants - Sonloup funicular, canton of Vaud, with an acquisition velocity of $6 \mathrm{~km} / \mathrm{h}$ and an acquisition distance ranging from 5 to $75 \mathrm{~m}$ with a GNSS SDI of 4 . Figure 11C shows a railway line section in the area of Montbovon, canton of Fribourg. The train velocity was $55 \mathrm{~km} / \mathrm{h}$, the acquisition distance was approximately $6 \mathrm{~m}$ and the GNSS SDI was 4. Figure 11D shows true colour point clouds that highlight the state of the walls and cliffs beside the motorway in the Seillon gorges, canton of Neuchattel. The acquisition velocity was $50 \mathrm{~km} / \mathrm{h}$, the acquisition distance was $12 \mathrm{~m}$ and the GNSS SDI was 2 . A helicopter flight above the village of Bondo, canton of Grisons, has facilitated quantifying the surface on the debris flow of 85,000 $\mathrm{m}^{2}$, which destroyed the village in August 2017, (Figure 11E) and creating an orthophoto. The flight velocity was $90 \mathrm{~km} / \mathrm{h}$ with an acquisition distance of approximately $350 \mathrm{~m}$ and a GNSS SDI of 3. Figure 11F shows the small alpine track of the Agites study site (canton of Vaud) where comparisons were made with the other seven sensors. The acquisition velocity was $15 \mathrm{~km} / \mathrm{h}$, the distance of acquisition was $3 \mathrm{~m}$ and the GNSS SDI was 2.

\section{Discussion}

The acquisition based on the proposed system permits surveying large distances along transportation tracks. The proposed system provides low cost and scaled 3D point clouds and an acceptable positioning. Nevertheless, as the process can be rather long, the surveys can be conducted without further processing, waiting until the necessity of creating a 3D view occurs to study a problem along a track.

Because the technique used here follows the track, the view is limited. It may be beneficial to couple SfM-EV with a UAV-based SfM approach that can provide surveys over larger areas around the tracks, for instance, to locate sources of natural hazards up to $500 \mathrm{~m}$ from the track. UAV-based SfM 
utility lies in the rockfall trajectory modelling from cliffs whose height is too large to be surveyed with SfM-EV from the road or the railway.

The results of the proposed system may be improved using single-lens reflex (SLR) camera sensors coupled with an external GNSS chip, providing a better localization performance since this configuration avoids rolling shutter effects and provides images with a better quality. The velocity of the acquisition could be thus certainly increased. In contrast, the costs of the system will significantly increase although they will still be much lower than cost of techniques using LiDAR technology, such as TLS, MLS or HMLS.

\subsection{Influence of the Velocity and the Distance of the Acquisition}

The acquisition distance of the SfM-EV has an influence on the image pixel size, on the point's density of the 3D point clouds and on the precision because it impacts the number of times a point of the scene is observed in the images. The pixel size on the ground (GSD, ground sample distance) increases linearly with the increase of the acquisition distance (Figure 9A) while the density of a point follows a negative power law of the distance (Figure 9B). The precision (SD) decreases linearly with the distance acquisition increasing according to the following equation (Figure 9C):

$$
\mathrm{SD} \text { of the precision error }=0.17 \times \text { acquisition distance }+0.5 \text {. }
$$

The number of times a point of the scene is observed in the images increases with the distance acquisition increase and this number decreases with velocity acquisition increase (Figure 10C,D).

The velocity has no influence on the pixel size. The density of a point decreases linearly with the velocity increase (Figure 9D) while the precision decreases exponentially with the velocity increase, increasing with the following equation (Figure 9E):

$$
\mathrm{SD} \text { of the precision error }=0.22 \times \mathrm{e}^{\text {(acquisition velocity } \times 0.09)} .
$$

\subsection{Pro and Cons of the Tested Techniques}

The main advantages of SfM-EV are its easy implementation, its acquisition velocity, its adaptation to almost all vehicles and its colourized and at-scale 3D point clouds, with positioning that can be acceptable for geoscientific purposes. No GCP are necessary to roughly georeference the scene. The main inconveniences are its lower precision than the LiDAR-based sensors and its considerable processing time, which can take several days for large images sets.

Compared to SfM-EV, low cost UAV-based SfM has the advantage of covering a greater surface area and thus is often able to survey the source areas of the natural hazards. Its disadvantages are a lower precision, a limited time flight and safety issues when it flies along transportation tracks, especially in steep topography with a low GNSS signal, tunnels and aerial cables. However, these characteristics are the rationale for using both techniques in a complementary manner. HMLS has the advantage of being more accurate than SfM techniques, especially for rough structures that are more or less smoothed with SfM techniques. However, the cost is much higher and is at present non-georeferenced. MLS has high precision, georeferenced clouds and the capability to survey with a high acquisition velocity. Its negative points are its very high cost, its heavy setup and its constraint regarding the calibration of the mobile system. The advantage of the ALS is that it is a ready to use product and it can be used as base for georeferencing but the point's density is too low to survey a slope along tracks. The advantages of STS are its very highly accurate georeferenced clouds but it is not designed to scan embankments for long distances and its price is high compared to the SfM-EV technique. TLS and LRTLS have similar advantages and disadvantages compared with STS but they generally cannot be automatically georeferenced. The main features of the tested survey techniques are presented in Table 7. 
Table 7. Summary of the features of the different tested techniques. Point density, average acquisition velocity, precision and accuracy data originate from the test on the Agites cliff beside a small and winding Alpine road.

\begin{tabular}{|c|c|c|c|c|c|c|c|c|c|c|c|}
\hline Technique & $\begin{array}{c}\text { Point } \\
\text { Density } \\
{\left[\mathrm{pts} / \mathrm{m}^{2}\right]}\end{array}$ & Range [m] & $\begin{array}{c}\text { Average } \\
\text { Acquisition } \\
\text { Velocity }[\mathrm{m} / \mathrm{h}]\end{array}$ & $\begin{array}{l}\text { Precision } \\
\text { [cm] }\end{array}$ & $\begin{array}{c}\text { Georeferencing } \\
{[\mathrm{m}]}\end{array}$ & $\begin{array}{c}\text { Topographic } \\
\text { Influence (Steep } \\
\text { Slope, Gorges) }\end{array}$ & $\begin{array}{c}\text { Setup } \\
\text { Time [min] }\end{array}$ & $\begin{array}{l}\text { Processing } \\
\text { Time }[\mathrm{h}]\end{array}$ & $\begin{array}{l}\text { Price EUR } \\
\text { (Hard and } \\
\text { Software) }\end{array}$ & Advantages & Disadvantages \\
\hline SfM-EV & 20,000 & 25 & 15,000 & 3 & 3 & $\begin{array}{c}\text { Loss of } \\
\text { georeferencing }\end{array}$ & 15 & 24 & 2000 & $\begin{array}{l}\text { Low-cost, acquisition } \\
\text { speed, colourized } \\
\text { point cloud, } \\
\text { georeferencing, many } \\
\text { support }\end{array}$ & $\begin{array}{c}\text { Accuracy, } \\
\text { processing time }\end{array}$ \\
\hline UAV SfM & 1500 & 50 & 10,000 & 5 & 5 & $\begin{array}{c}\text { Loss of } \\
\text { georeferencing }\end{array}$ & 5 & 18 & 2500 & $\begin{array}{l}\text { Low-cost, acquisition } \\
\text { speed, colourized } \\
\text { point cloud, } \\
\text { georeferencing }\end{array}$ & $\begin{array}{c}\text { Accuracy, } \\
\text { processing time }\end{array}$ \\
\hline Handheld LiDAR & 4500 & 10 & 2000 & 3 & No & No & 5 & 0.25 & 50,000 & $\begin{array}{l}\text { Installation and } \\
\text { processing time, } \\
\text { acquisition speed, } \\
\text { easy to use }\end{array}$ & $\begin{array}{l}\text { No colourized point } \\
\text { cloud }\end{array}$ \\
\hline Mobile LiDAR & 5000 & 2000 & 20,000 & 3 & 0.5 & $\begin{array}{c}\text { Loss of } \\
\text { georeferencing }\end{array}$ & 90 & 4 & 300,000 & $\begin{array}{l}\text { Acquisition speed, } \\
\text { accuracy, } \\
\text { georeferencing }\end{array}$ & $\begin{array}{l}\text { Cost, installation } \\
\text { and processing time }\end{array}$ \\
\hline $\begin{array}{l}\text { Scanning total } \\
\text { station }\end{array}$ & 38,500 & 600 & 200 & 0.5 & 0.1 & Any & 15 & 1 & 70,000 & $\begin{array}{c}\text { Accuracy, } \\
\text { georeferencing }\end{array}$ & Acquisition speed \\
\hline $\begin{array}{l}\text { Static long-range } \\
\text { LiDAR }\end{array}$ & 47,000 & 1500 & 100 & 2 & No & No & 15 & 2 & 100,000 & $\begin{array}{l}\text { Accuracy, point } \\
\text { density }\end{array}$ & $\begin{array}{c}\text { Cost, acquisition } \\
\text { time, georeferencing }\end{array}$ \\
\hline Static LiDAR & 24,000 & 300 & 100 & 1 & No & No & 20 & 2 & 150,000 & $\begin{array}{l}\text { Accuracy, point } \\
\text { density }\end{array}$ & $\begin{array}{l}\text { Cost, acquisition } \\
\text { time, georeferencing }\end{array}$ \\
\hline Airborne LiDAR & 2.5 & - & 100,000 & 5 & 0.2 & $\begin{array}{l}\text { Loss of point } \\
\text { density }\end{array}$ & - & - & $10 / \mathrm{km}^{2}$ & $\begin{array}{l}\text { Acquisition speed, } \\
\text { georeferencing }\end{array}$ & $\begin{array}{l}\text { Accuracy, point } \\
\text { density, depends of } \\
\text { a third party }\end{array}$ \\
\hline
\end{tabular}


All the geolocalization by GNSS (SfM-EV, UAV-SfM and mobile LiDAR) can be constrained by obstructions because of steep topography or high vegetation above the track. European GNSS service Galileo could significantly improve the georeferencing when the GNSS chips in the sensors will be compatible with it and when the European system will reach its expected accuracy by approximately 2020 [60].

Even if SfM-EV colourized point clouds are more smoothed than LiDAR point clouds, their well-detailed colours help to visually detect geological features (fails, vegetation such as moss, water outflows, wet sections, etc.)

\subsection{Perspectives}

Hardware and software used in SfM may still improve and are continuously being developed [61]. With these improvements, it will take less time to process images in the near future and archiving will not be a problem. Thus, it appears that it is possible to collect many tracksides images and to process them only if there will be an interest in the future. An example could be a temporal comparison of the track embankment state, with images taken before and after an event such as a landslide that has damaged the track embankment. These stored images can always be processed in the future using an improved version of the SfM processing software, likely generating more precise results an interest arises to compare or to analyse the 3D topography of the captured tracksides.

One of the main evolutions will be within the camera systems and the GNSS. The resolution and the positioning will be improved as well as the optics. Our observations confirmed this during the last three years while continually acquiring new cameras that possessed improved capabilities.

Improvements can be made henceforth on the installation, positioning of cameras on vehicles and on the velocity of acquisition, particularly for surveys on railway sides. All tests were carried out using normal trains that drive with their normal velocities. Using a special train with an appropriate velocity of acquisition and with an adapted wagon to avoid the sky obstruction as well as the track and embankment due to the train body obstruction will improve the results resolution, precision and accuracy.

Mobile remote sensing sensors are the key in slope surveys along the transportation tracks. With the high potential and advancements of the SfM technique and the computing capacities, the use of modern photogrammetry for slopes along roads and railways will likely continue to grow in the next years. SfM-EV also has the potential for improvement in the domain of automatic georeferencing with the future integration of the Galileo GNSS constellation in camera chips. The acquisition of GPS, GLONASS and Galileo constellations will not only improve the georeferencing accuracy but also the capacity to receive enough satellite signals in difficult locations, such as in deep gorges or under sparse vegetation. It can also be expected that SfM developments will allow producing 3D models in real time. In the long term, this real-time SfM might also be conducted using small devices, such as smartphones. One progress for the georeferencing will be to include an inertial measurement unit (IMU) within or associated with the cameras.

While traditional mobile LiDAR systems are very expensive and highly demanding to set up, they have been, for a few years, in competition with the low cost SfM system, particularly the presented SfM-EV technique. However, mobile LiDAR systems will most likely have a new momentum with the near future democratization of LiDAR sensors in the automotive domain [62]. The first cars with embedded LiDAR have been on the market since 2017. This new LiDAR usage will, in any ways, motivate the quite conservative world of LiDAR developers and help to reduce the price. Furthermore, UAV-based LiDAR launched in the last few years has become more popular, such as the RiCOPTER from RIEGL or the handheld LiDAR tested during this project. That could foster, in the near future, a new impetus to the LiDAR technology.

For now, and in the near future, the SfM technique will likely mature by coupling with LiDAR [63]. Combining both techniques could encompass the best of both techniques. The advantages of SfM 
are notably its low cost, its ease of use and its capacity to model large surfaces in colours. Some disadvantages are its structure smoothing and its lower precision than the LiDAR approaches.

\section{Conclusions}

Experiences acquired with SfM-EV during the last years, with more than two hundred scenes processed to survey transportation tracksides, have allowed us to validate this technique based on a low cost of materials (approximately 2000 EUR for the complete system with four cameras and the mast) compared to professional systems, for instance, that used by Google [45]. Adding a camera with a GNSS chip has greatly improved the interest of the SfM-EV, providing the possibility to obtain a georeferencing of 3D point clouds sufficient for many geoscience applications, often based on the change detection. The techniques can also to be used to survey different infrastructures, such as road signs on the ground, urban vandalism, wall and drainage surveys, snow height and volume on tracksides and so on, all of which require 3D coloured modelling. The results of the tests highlight that the best results are obtained with an acquisition speed below $25 \mathrm{~km} / \mathrm{h}$ and a distance of acquisition below $20 \mathrm{~m}$, for the present configuration of GoPro cameras, which will certainly be improved.

One of the distinctions of the SfM-EV technique is its automatic georeferencing without GCP or RTK-GNSS, in contrast to the common SfM used in the geosciences $[20,64,65]$. The localized images from two cameras with an embedded GNSS chip allow obtaining a 3D accuracy of a few metres, depending on the sky obstruction. If this accuracy cannot be sufficient for measurements of precise slope movements, it is sufficient in most of the geosciences case studies because they are concerned mainly with significant change detection $(>5 \mathrm{~cm})$ which does not require an absolute accuracy but only a scaling of the SfM point cloud. Furthermore, due to the track geometry (road width, track gauge, etc.), it is possible to improve the georeferencing and scaling using the location of points and distances measured from aerial images.

The precision ( $2 \mathrm{~cm}$ on a $350 \mathrm{~m}^{2}$ cliff) obtained from SfM-EV techniques is between a static sensor accuracy such as static LiDAR $(1 \mathrm{~cm})$ and a mobile sensor such as a mobile laser scanner $(2 \mathrm{~cm})$. The expected georeferencing accuracy is below $5 \mathrm{~m}$ for the sky with a low obstruction (for instance, $20 \mathrm{~m}$ from the edge of a forest) and below $10 \mathrm{~m}$ for the sky with a medium obstruction (for example, at the foot of a high cliff or when a few branches of trees cover the track). The accuracy and precision results have demonstrated that SfM-EV is a valuable survey technique which can be compared to traditional ones such as LiDAR. Since SfM-EV acquisitions depend on many factors such as brightness, shadow, vegetation cover above track, acquisition velocity and distance, the results may vary and can almost never be certified before treatment but it can be anticipated with experience. SfM-EV is, in any case, a potentially inexpensive technique to survey tracks, especially for services that have a low budget with a cost of approximately 150 times smaller than a mobile LiDAR approach.

We are aware that best results to survey slopes are obtained with traditional survey techniques but SfM-EV is generally enough for a first survey approach that can readily highlight slope changes of a cube of one litre, as demonstrated by the present results (see Section 3). If the required precision is not reached with this technique, using a traditional technique is necessary, for example, to survey with a sub-centimetric precision. However, the majority of slope surveys do not demand such a high precision; thus, SfM-EV can be of great interest.

Author Contributions: J.V., M.J. and M.-H.D. led this study. J.V. wrote the paper under the supervision of M.J. and M.-H.D., P.B. and J.-P.M. realized the on-field acquisition with the MLS system and provided data from MLS.

Funding: This research received no external funding.

Acknowledgments: The authors would especially like to thank Fabien Coubard and Ivo Pfammater from ALLNAV ag for the Trimble SX10 STS loan and introductory course. The authors would also thank Anthony Monnier from the MOB, Compagnie du Chemin de fer Montreux Oberland Bernois, for making possible to install the camera on the MOB trains. The English language of a previous version of this paper was corrected by the American Journal Experts. The authors would also like to thank to the reviewers for their reviews and valuable comments. 
Conflicts of Interest: The authors declare no conflict of interest.

\section{References}

1. Bunce, C.M.; Cruden, D.M.; Morgenstern, N.R. Assessment of the hazard from rock fall on a highway. Can. Geotech. J. 1997, 34, 344-356. [CrossRef]

2. Nicholson, A.; Du, Z.-P. Degradable transportation systems: An integrated equilibrium model. Transp. Res. Part B Methodol. 1997, 31, 209-223. [CrossRef]

3. Hungr, O.; Evans, S.G.; Hazzard, J. Magnitude and frequency of rock falls and rock slides along the main transportation corridors of southwestern British Columbia. Can. Geotech. J. 1999, 36, 224-238. [CrossRef]

4. Dalziell, E.; Nicholson, A. Risk and impact of natural hazards on a road network. J. Transp. Eng. 2001, 127, 159-166. [CrossRef]

5. Budetta, P. Assessment of rockfall risk along roads. Nat. Hazards Earth Syst. Sci. 2004, 4. [CrossRef]

6. Evans, S.G.; Cruden, D.M.; Bobrowsky, P.T.; Guthrie, R.H.; Keegan, T.R.; Liverman, D.G.E.; Perret, D. Landslide risk assessment in Canada: A review of recent developments. In Landslide Risk Management; Hungr, O., Fell, R., Couture, R., Eberhardt, E., Eds.; Taylor and Francis: London, UK, 2005; pp. 351-363, ISBN 9780415380430.

7. Karlaftis, M.G.; Kepaptsoglou, K.L.; Lambropoulos, S. Fund allocation for transportation network recovery following natural disasters. J. Urban Plan. Dev. 2007, 133, 82-89. [CrossRef]

8. Collins, T.K. Debris flows caused by failure of fill slopes: Early detection, warning, and loss prevention. Landslides 2008, 5, 107-120. [CrossRef]

9. Tatano, H.; Tsuchiya, S. A framework for economic loss estimation due to seismic transportation network disruption: A spatial computable general equilibrium approach. Natl. Hazards 2008, 44, 253-265. [CrossRef]

10. Erath, A.; Birdsall, J.; Axhausen, K.; Hajdin, R. Vulnerability assessment methodology for Swiss road network. J. Transp. Res. Board 2008, 2137, 118-126. [CrossRef]

11. Salcedo, D.A. Behavior of a landslide prior to inducing a viaduct failure, Caracas-La Guaira highway, Venezuela. Eng. Geol. 2009, 109, 16-30. [CrossRef]

12. Muzira, S.; Humphreys, M.; Wolfhart, P. Geohazard Management in the Transport Sector; Transport Notes Series; World Bank: Washington, DC, USA, 2010; Volume 40, Available online: https: / / openknowledge.worldbank. org/handle/10986/11708 (accessed on 25 January 2018).

13. Guemache, M.A.; Chatelain, J.-L.; Machane, D.; Benahmed, S.; Djadia, L. Failure of landslide stabilization measures: The Sidi Rached viaduct case (Constantine, Algeria). J. Afr. Earth Sci. 2011, 59, 349-358. [CrossRef]

14. Jaiswal, P.; van Westen, C.J.; Jetten, V. Quantitative assessment of landslide hazard along transportation lines using historical records. Landslides 2011, 8, 279-291. [CrossRef]

15. Jenelius, E.; Mattsson, L.G. Road network vulnerability analysis of area-covering disruptions: A grid-based approach with case study. Transp. Res. Part A Policy Pract. 2012, 46, 746-760. [CrossRef]

16. Michoud, C.; Derron, M.-H.; Horton, P.; Jaboyedoff, M.; Baillifard, F.-J.; Loye, A.; Nicolet, P.; Pedrazzini, A.; Queyrel, A. Rockfall hazard and risk assessments along roads at a regional scale: Example in Swiss Alps. Nat. Hazards Earth Syst. Sci. 2012, 12, 615-629. [CrossRef]

17. Laimer, H.J. Anthropogenically induced landslides-A challenge for railway infrastructure in mountainous regions. Eng Geol. 2017, 222, 92-101. [CrossRef]

18. Bouali, E.H.; Oommen, T.; Vitton, S.; Escobar-Wolf, R.; Brooks, C. Rockfall hazard rating system: Benefits of utilizing remote sensing. Environ. Eng. Geosci. 2017, 23, 165-177. [CrossRef]

19. Abellán, A.; Derron, M.-H.; Jaboyedoff, M. Use of 3D Point Clouds in Geohazards, Special Issue: Current Challenges and Future Trends. Remote Sens. 2016, 8. [CrossRef]

20. Westoby, M.J.; Brassington, J.; Glasser, N.F.; Hambrey, M.J.; Reynolds, J.M. "Structure-from-Motion" photogrammetry: A low-cost, effective tool for geoscience applications. Geomorphology 2012, 179, 300-314. [CrossRef]

21. Voumard, J.; Abellán, A.; Nicolet, P.; Penna, I.; Chanut, M.-A.; Derron, M.-H.; Jaboyedoff, M. Using street view imagery for 3-D survey of rock slope failures. Nat. Hazards Earth Syst. Sci. 2017, 17, 2093-2107. [CrossRef]

22. Rosser, N.J.; Petley, D.N.; Lim, M.; Dunning, S.A.; Allison, R.J. Terrestrial laser scanning for monitoring the process of hard rock coastal cliff erosion. Q. J. Eng. Geol. Hydrog. 2005, 38, 363-375. [CrossRef] 
23. Oppikofer, T.; Jaboyedoff, M.; Blikra, L.; Derron, M.-H.; Metzger, R. Characterization and monitoring of the Åknes rockslide using terrestrial laser scanning. Nat. Hazards Earth Syst. Sci. 2009, 9, 1003-1019. [CrossRef]

24. Fey, C.; Wichmann, V. Long-range terrestrial laser scanning for geomorphological change detection in alpine terrain-Handling uncertainties. Earth Surf. Proc. Landf. 2017, 42, 789-802. [CrossRef]

25. Walstra, J.; Chandler, J.H.; Dixon, N.; Dijkstra, T.A. Aerial photography and digital photogrammetry for landslide monitoring. Geol. Soc. Lond. Spec. Publ. 2007, 283, 53-63. [CrossRef]

26. Lucieer, A.; de Jong, S.; Turner, D. Mapping landslide displacements using Structure from Motion (SfM) and image correlation of multi-temporal UAV photography. Prog. Phys. Geog. 2013, 38, 97-116. [CrossRef]

27. Fernández, T.; Pérez, J.L.; Cardenal, J.; Gómez, J.M.; Colomo, C.; Delgado, J. Analysis of Landslide Evolution Affecting Olive Groves Using UAV and Photogrammetric Techniques. Remote Sens. 2016, 8, 837. [CrossRef]

28. Guerin, A.; Abellán, A.; Matasci, B.; Jaboyedoff, M.; Derron, M.-H.; Ravanel, L. Brief communication: 3-D reconstruction of a collapsed rock pillar from Web-retrieved images and terrestrial lidar data-The 2005 event of the west face of the Drus (Mont Blanc massif). Nat. Hazards Earth Syst. Sci. 2017, 17, 1207-1220. [CrossRef]

29. Ruggles, S.; Clark, J.; Franke, K.W.; Wolfe, D.; Reimschiissel, B.; Martin, R.A.; Okeson, T.J.; Hedengren, J.D. Comparison of SfM computer vision point clouds of a landslide derived from multiple small UAV platforms and sensors to a TLS based model. J. Unmanned Veh. Syst. 2016, 4, 246-265. [CrossRef]

30. Abellán, A.; Oppikofer, T.; Jaboyedoff, M.; Rosser, N.J.; Lim, M.; Lato, M.J. Terrestrial laser scanning of rock slope instabilities. Earth Surf. Proc. Land. 2014, 39, 80-97. [CrossRef]

31. Carrivick, J.L.; Smith, M.W.; Quincey, D.J. Structure from Motion in the Geosciences; Wiley-Blackwell: Oxford, UK, 2016; p. 208. ISBN 978-1-118-89584-9.

32. Klingner, B.; Martin, D.; Roseborough, J. Street view motion-from-structure-from-motion. In Proceedings of the IEEE International Conference on Computer Vision (ICCV), Sydney, Australia, 1-8 December 2013; pp. 953-960.

33. Bemis, S.P.; Micklethwaite, S.; Turner, D.; James, M.R.; Akciz, S.; Thiele, S.T.; Bangash, H.A. Ground-based and UAV-based photogrammetry: A multi-scale, high-resolution mapping tool for structural geology and paleoseismology. J. Struct. Geol. 2014, 69, 163-178. [CrossRef]

34. Green, S.; Bevan, A.; Shapland, M. A comparative assessment of structure from motion methods for archaeological research. J. Archaeol. Sci. 2014, 46, 173-181. [CrossRef]

35. Debevec, P.E.; Taylor, C.J.; Malik, J. Modeling and rendering architecture from photographs: A hybrid geometry-and image-based approach. In Proceedings of the 23rd Annual Conference on Computer Graphics and Interactive Techniques; ACM: New York, NY, USA, 1996; pp. 11-20.

36. Rokhmana, C.A. The potential of UAV-based remote sensing for supporting precision agriculture in Indonesia. Procedia Environ. Sci. 2015, 24, 245-253. [CrossRef]

37. Brostow, G.J.; Shotton, J.; Fauqueur, J.; Cipolla, R. Segmentation and recognition using structure from motion point clouds. In European Conference on Computer Vision; Springer: Berlin/Heidelberg, Germany, 2008; pp. 44-57.

38. James, M.R.; Robson, S. Straightforward reconstruction of 3D surfaces and topography with a camera, Accuracy and geosciences application. J. Geophys. Res. 2012, 117, F03017. [CrossRef]

39. Lowe, D. Object recognition from local scale-invariant features. In Proceedings of the International Conference of Computer Vision, Kerkyra, Greece, 20-27 September 1999; pp. 1150-1157.

40. Snavely, N. Scene Reconstruction and Visualization from Internet Photo Collections. Ph.D. Thesis, University of Washington, Seattle, WA, USA, 2008.

41. Favalli, M.; Fornaciai, A.; Isola, I.; Tarquini, S.; Nannipieri, L. Multiview 3D reconstruction in geosciences. Comput. Sci. 2011, 44, 168-176. [CrossRef]

42. Turner, D.; Lucieer, A.; Watson, C. An automated technique for generating georectified mosaics from ultra-high resolution unmanned aerial vehicle (UAV) imagery, based on structure from motion (SfM) point clouds. Remote Sens. 2014, 4, 1392-1410. [CrossRef]

43. Furukawa, Y.; Ponce, J. Accurate, dense, and robust multiview stereopsis. IEEE Trans. Pattern Anal. 2010, 32, 1362-1376. [CrossRef] [PubMed]

44. Furukawa, Y.; Curless, B.; Seitz, S.M.; Szeliski, R. Towards internet-scale multi-view stereo. In Proceedings of the IEEE Conference on Computer Vision and Pattern Recognition (CVPR), San Francisco, CA, USA, 13-18 June 2010; pp. 1434-1441. 
45. Anguelov, D.; Dulong, C.; Filip, D.; Frueh, C.; Lafon, S.; Lyon, R.; Ogale, A.; Vincent, L.; Weaver, J. Google Street View: Capturing the world at street level. IEEE Comput. 2010, 43, 32-38. [CrossRef]

46. Hero3+ Silver GoPro. Available online: https://gopro.com/content/dam/help/hero3plus-silver-edition/ manuals/UM_H3PlusSilver_ENG_REVB_WEB.pdf (accessed on 25 January 2018).

47. Garmin. Virb XE. Available online: http://static.garmin.com/pumac/virbX_OM_EN.pdf (accessed on 25 January 2018).

48. GoPro. Hero4 Silver. Available online: https://gopro.com/content/dam/help/hero4-silver/manuals/UM_ H4Silver_ENG_REVA_WEB.pdf (accessed on 25 January 2018).

49. GoPro. Hero5 Black GoPro. Available online: https://gopro.com/content/dam/help/hero5-black/ manuals/HERO5Black_UM_ENG_REVC_Web.pdf (accessed on 25 January 2018).

50. Agisoft, L.L.C. Agisoft PhotoScan User Manual, Professional Edition, Version 1.4.4; Agisoft LLC: St. Petersburg, Russia, 2018.

51. ASIT-VD. LiDAR 2015: Points Bruts Classifiés. Available online: https:/ /www.asitvd.ch/index.php?option= com_easysdi_catalog\&view=sheet\&guid=9ea9af65-e9a8-4974-41d4-fcc2f50e9dba\&catalog=main\&type= complete\&preview=search_list (accessed on 25 January 2018).

52. DJI. DJI Phantom 4 pro +. Available online: https://dl.djicdn.com/downloads/phantom_4_pro/20171017/ Phantom_4_Pro_Pro_Plus_User_Manual_EN.pdf (accessed on 25 January 2018).

53. RIEGL. RIEGL VMZ Infosheet. Available online: http:/ / www.riegl.com/uploads/tx_pxpriegldownloads / VMZ-at-a-glance_2017-12-05.pdf (accessed on 25 January 2018).

54. GeoSlam. GeoSlam Zeb-Revo. Available online: https://geoslam.com/hardware/zeb-revo (accessed on 25 January 2018).

55. Trimble. Trimble SX10. Available online: https://geospatial.trimble.com/products-and-solutions/sx10\# product-support (accessed on 25 January 2018).

56. Leica. Leica ScanStation 2. Available online: http://hds.leica-geosystems.com/downloads123/hds/hds/ ScanStation/brochures-datasheet/Leica_ScanStation\%202_datasheet_en.pdf (accessed on 25 January 2018).

57. Swisstopo. Geo.admin.ch-The Federal Geoportail. Available online: https://www.geo.admin.ch/en/home. html, (accessed on 25 January 2018).

58. Girardeau-Montaut, D. CloudCompare (Version 2.9), GPL Software. Available online: http://www. cloudcompare.org (accessed on 25 January 2018).

59. Swisstopo: Swipos-GIS/GEO. Available online: www.swisstopo.ch/swipos (accessed on 25 January 2018).

60. Nurmi, J.; Lohan, E.S.; Sand, S.; Hurskainen, H. Galileo Positioning Technology; Springer: Berlin, Germany, 2015; Volume 176.

61. Javernick, L.; Brasington, J.; Caruso, B. Modeling the topography of shallow braided rivers using Structure-from-Motion photogrammetry. Geomorphology 2014, 213, 166-182. [CrossRef]

62. Bimbraw, K. Autonomous Cars: Past, Present and Future A Review of the Developments in the Last Century, the Present Scenario and the Expected Future of Autonomous Vehicle Technology. Inform. Control Autom. Robot. 2015, 1, 191-198.

63. Assali, P.; Grussenmeyer, P.; Villemin, T.; Pollet, N.; Viguier, F. Surveying and modeling of rock discontinuities by terrestrial laser scanning and photogrammetry: Semiautomatic approaches for linear outcrop inspection. J. Struct. Geol. 2014, 66, 102-114. [CrossRef]

64. Niethammer, U.; James, M.R.; Rothmund, S.; Travelletti, J.; Joswig, M. UAV-based remote sensing of the Super-Sauze landslide: Evaluation and results. Eng. Geol. 2012, 128, 2-11. [CrossRef]

65. Turner, D.; Lucieer, A.; Wallace, L. Direct georeferencing of ultrahigh-resolution UAV imagery. IEEE Trans. Geosci. Remote Sens. 2014, 52, 2738-2745. [CrossRef]

(C) 2018 by the authors. Licensee MDPI, Basel, Switzerland. This article is an open access article distributed under the terms and conditions of the Creative Commons Attribution (CC BY) license (http:/ / creativecommons.org/licenses/by/4.0/). 